\title{
Venous thromboembolism - recommendations on the prevention, diagnostic approach and management. The 2017 Polish Consensus Statement
}

\author{
Witold Tomkowski', Paweł Kuca', Tomasz Urbanek², Dariusz Chmielewski', \\ Zbigniew Krasiński ${ }^{4}$, Piotr Pruszczyk ${ }^{5}$, Jerzy Windyga ${ }^{6}$, Grzegorz Oszkinis ${ }^{4}$, Arkadiusz Jawieńn ${ }^{7}$, \\ Janusz Burakowski', Małgorzata Dybowska', Jan Kęsik ${ }^{8}$, Tomasz Zubilewicz ${ }^{8}$ \\ 'Intensive Pulmonary and Cardiac Care, Institute of Tuberculosis and Lung Disease, Warsaw, Poland \\ ${ }^{2}$ Chair and Department of General and Vascular Surgery, Angiology, and Phlebology, Medical University of Silesia, \\ Katowice, Poland \\ ${ }^{3}$ Orthopedic Surgery and Traumatology Service, HOSPITEN Lanzarote, Puerto del Carmen, Spain \\ ${ }^{4}$ Department of General and Vascular Surgery, Poznań University of Medical Science, Poznań, Poland \\ ${ }^{5}$ Department of Internal Medicine and Cardiology with the Centre for Management of Venous Thromboembolic Disease, \\ Medical University of Warsaw, Warsaw, Poland \\ ${ }^{6}$ Department of Disorders of Hemostasis and Internal Medicine, Institute of Hematology and Transfusion Medicine, \\ Warsaw, Poland \\ ${ }^{7}$ Chair and Department of Vascular Surgery and Angiology, Ludwik Rydygier Collegium Medicum in Bydgoszcz, \\ Nicolaus Copernicus University, Bydgoszcz, Poland \\ ${ }^{8}$ Chair and Department of Vascular Surgery and Angiology, Medical University of Lublin, Lublin, Poland
}

\begin{abstract}
The 2017 Polish Consensus Statement (PCS 2017) includes updated recommendations on the prevention, diagnostic approach, and management of venous thromboembolism (VTE). For VTE without cancer, the authors of PCS 2017 recommend apixaban, edoxaban, rivaroxaban, and dabigatran over vitamin Kantagonists (VKA) as long-term anticoagulant therapy. For VTE with cancer, the authors of PCS 2017 recommend low molecular weight heparins (LMWH) over VKA, apixaban, edoxaban, rivaroxaban and dabigatran. For extended secondary prevention of deep venous thrombosis (DVT), PCS 2017 recommends apixaban, edoxaban, rivaroxaban, dabigatran, VKA, and sulodexide. For extended secondary prevention of pulmonary embolism (PE), PCS 2017 recommends apixaban, edoxaban, rivaroxaban, dabigatran and VKA. For extended secondary prevention in patients with idiopathic DVT and a high risk of bleeding complications, the authors of PCS 2017 recommend NOT to stop anticoagulation and use sulodexide. For extended secondary prevention in patients with idiopathic PE and a high risk of bleeding, the authors of PCS 2017 recommend NOT to stop anticoagulation and suggest treatment with apixaban, edoxaban, rivaroxaban, and dabigatran in reduced doses adjusted to the risk of bleeding. For VTE treated with anticoagulants, PCS 2017 recommends against insertion of a vena cava filter. For patients with DVT, PCS 2017 suggests USING compression stockings routinely to prevent postthrombotic syndrome. For subsegmental PE without proximal DVT, PCS 2017 suggests clinical surveillance over anticoagulation with a low risk of recurrent VTE, and anticoagulation over clinical surveillance with a high risk of recurrent VTE. The 20 I 7 Polish Consensus Statement suggests thrombolytic therapy for PE with hypotension, and systemic therapy over catheter-directed thrombolysis. For recurrent VTE on a non-LMWH anticoagulant, PCS 2017 suggests LMWH, and for recurrent DVT and/or PE on LMWH, PCS 2017 suggests increasing the dose of LMWH.
\end{abstract}

Address for correspondence: Prof. Witold Tomkowski, MD, PhD, Intensive Pulmonary and Cardiac Care, Institute of Tuberculosis and Lung Disease, Warsaw, Poland, ul. Płocka 26, 0I-138 Warszawa, Poland 
Key words: venous thromboembolism, pulmonary embolism, deep venous thrombosis, anticoagulation

Acta Angiol 20I 7; 23, 2: 35-7I

\section{The 2017 Polish Consensus Statement}

The 2017 Polish Consensus Statement (PCS 2017) summarizes the recommendation of Polish experts regarding the prevention of, diagnostic approach to, and the management of venous thromboembolism (VTE).

The 2017 Polish Consensus Statement has been based on the analysis of the literature data and the international and national guidelines, in particular the 2016 American College of Chest Physicians (ACCP) guidelines, and the opinion of Polish experts [1,2].

Each recommendation included in PCS 2017 has been discussed and accepted by a representative panel of Polish specialists listed above. The 2017 Polish Consensus Statement recommendations include considerations specific to the Polish settings and differ in many details from the 2016 ACCP guidelines. The 2017 Polish Consensus Statement is based on the most recent literature, including papers from 2016 and 2017 which were not available for the experts who developed the ACCP guidelines.

Of note, numerous papers published in 201 I-2017 greatly expanded our knowledge on the prevention of, diagnostic approach to, and the management of VTE. This evidence has been the basis for the present updated recommendations.

\section{Disclaimer}

All attempts were made to provide the most update and precise information as of the time of the publication. Determination of the optimal management of a specific patients remains the sole responsibility of the treating physician. The authors, editors, and publishers do not bear any responsibility for any legal matters that might arise when citing the present statement.

The 2017 Polish Consensus Statement will be published on the website of Polska Fundacja do Walki z Zakrzepicą „Thrombosis" (available freely at www. thrombosis.pl, go to the tab "Konsensus Polski") which initiated the work on the present statement.

Before prophylactic or therapeutic use of any anticoagulant, the summary of product characteristics (SPC) prepared by the drug manufacturer should be carefully consulted.

\section{Levels of evidence and classes of recommendations}

Class A recommendations are based on the evidence from randomized controlled trials which provided consistent results (e.g., in systematic reviews) and were performed directly in the target population. Recommendations based on a single but very reliable randomized clinical trial which included more patients than previous studies have also been categorized as class $\mathrm{A}$.

Class B recommendations are based on the evidence from randomized controlled trials which were performed directly in the target population and provided less consistent results, had limited statistical power or were associated with other methodological problems. Class B recommendations are also based on the evidence from randomized controlled trials which were extrapolated from other patient group to the target population.

Class $\mathbf{C}$ recommendations are based on the evidence from well-conducted observational studies which provided consistent results and were performed directly in the target population.

Class $\mathrm{Cl}$ recommendations are based on the opinion of Polish experts who authored PCS 2017, resulting from studies or observations in the Polish population.

The 2017 Polish Consensus Statement recommendations were also adjusted to the logistic capabilities of Polish hospital units, clinics, and ambulatory care.

\section{Introduction}

Deep venous thrombosis (DVT) and pulmonary embolism (PE) are major health problems which may lead to serious consequences. Acute PE may be fatal. In the long-term, recurrent PE may lead to pulmonary hypertension. Inadequate attention is often paid to postthrombotic chronic venous disease which is a consequence of DVT in some patients. Chronic venous disease is associated with venous congestion, venous obstruction, skin changes, and ulcerations which have a negative effect on quality of life and contribute to increased healthcare costs. 
The annual incidence of venous thromboembolism (VTE) in the developed countries is about 200-300 per 100,000 population. In Northern America and Europe, the annual incidence of DVT is about 160-200 per 100,000 population, the incidence of symptomatic $\mathrm{PE}$ is $50-100$ per 100,000 population, and the incidence of fatal PE detected during autopsy is 50 per 100,000. The prevalence of venous ulcerations is at least 300 per 100,000 , and about $25 \%$ of cases of chronic venous disease result from DVT. The total annual cost of treating chronic venous disease in Western Europe has been estimated at 600-900 million euro, amounting to $\mathrm{I}-2 \%$ of all healthcare budget in these countries.

The concept of Virchow triad which defines factors predisposing to VTE, including venous congestion, changes in blood components, and endothelial damage, is as valid nowadays as when it was introduced in the $19^{\text {th }}$ century. Development of VTE often requires concomitant presence of at least two factors. Major clinical predisposing factors include immobilization, trauma, surgery, infection, pregnancy (particularly with in vitro fertilization), and the postpartum period. Other predisposing factors include age above 40 years, malignancy, previous venous thrombosis or PE, dehydration, hormonal therapy, varicose veins, obesity, and thrombophilias. The nature of the risk factor (acute or chronic) dictates the management approach and the duration of treatment.

Hospitalized patients are at particular risk of VTE, also including those patients who have already been discharged from the hospital. Although VTE is an attractive target for maximally effective prevention, achieving the success is difficult. Best use of prevention methods should be achieved with repeated educational efforts combined with a system of incentives, warnings, and if possible, also computerized electronic alarms.

Increasing patients' awareness of risks associated with VTE is a task and target the achievement of which may significantly improve treatment outcomes [3].

\section{Primary prevention of VTE}

\section{General surgery}

Surgical patients at an increased risk of thromboembolic complications. However, the risk of perioperative and postoperative DVT is related not only to the type of surgical procedure but also to other concomitant risk factors, the clinical importance of which may be much higher than the risk associated with a specific surgical procedure.

The risk of thromboembolic complications in surgical patients is also increased by age, malignancy and/ lor cancer treatment, previous venous thrombosis, varicose veins, thrombophilias, and obesity. The risk of thrombosis also depends on the type and duration of surgery, type of anesthesia, duration of immobilization, and other concomitant risk factors such as inflammatory bowel disease, acute infection, or sepsis.

In the context of patient referral for surgical treatment and initiation of thromboprophylaxis, individual assessment of the risk of thromboembolic complications and the bleeding risk is thus important in patients considered candidates for surgical treatment. VTE risk assessment models for both surgical and non-surgical patients are available in the literature. When implementing these models in practice, validation of their accuracy and effectiveness in specific clinical scenarios and patient groups should be taken into account.

Among risk stratification systems developed for general surgical patients, a risk assessment model proposed by Caprini may be noted (Table I). When using this model, however, one should remember that it was validated in only some surgical patient populations. In other surgical specialties, such as urology, thoracic surgery and vascular surgery, no uniform systems to evaluate VTE risk are available yet due to different patient characteristics. For these reasons, individualized assessment of VTE risk is needed in all cases, taking into account both the procedure-related risk and the risk associated with other concomitant individual risk factors.

Based on known clinical risk factors, patients may be categorized into high, moderate, or low VTE risk groups.

Studies indicate that in some surgical patients, VTE risk remains elevated also after hospital discharge. This is the case mostly in patients undergoing major abdominal and pelvic surgery, particularly in surgical cancer patients.

Introduction of minimally invasive surgical approaches, including endoscopic and laparoscopic procedures, which are associated with shorter duration of postoperative immobilization, has had a significant effect on the potential reduction of procedure-related VTE risk but it does not eliminate this risk completely, particularly with the presence of multiple concomitant VTE risk factors.

Significant factors increasing the likelihood of thromboembolic complications which are associated with VTE risk directly related to the type of laparoscopic procedure include laparoscopic procedures within the pelvis, prolonged laparoscopic procedures, and oncological laparoscopic procedures.

\section{Recommendations}

The low risk group includes patients without significant risk factors undergoing minor surgical procedures (Caprini score I-2, Table I). Limited data from prospective randomized trials are available on the efficacy 
Table I. The Caprini model to evaluate venous thromboembolism risk

\begin{tabular}{|c|c|c|c|}
\hline I point & 2 points & 3 points & 5 points \\
\hline $\begin{array}{l}\text { Age } 4 \text { I to } 60 \text { years } \\
\text { Minor surgery } \\
\text { BMI > } 25 \mathrm{~kg} / \mathrm{m} \\
\text { Swollen legs } \\
\text { Varicose veins } \\
\text { Pregnancy or postpartum } \\
\text { History of unexplained or re- } \\
\text { current spontaneous abortion } \\
\text { Oral contraceptives or hor- } \\
\text { mone replacement } \\
\text { Sepsis (< I month) } \\
\text { Serious lung disease, including } \\
\text { pneumonia (< I month) } \\
\text { Abnormal pulmonary function } \\
\text { Acute myocardial infarction } \\
\text { Congestive heart failure } \\
\text { (< I month) } \\
\text { History of inflammatory bowel } \\
\text { disease } \\
\text { Medical patient at bed rest }\end{array}$ & $\begin{array}{l}\text { Age } 6 \mathrm{I} \text { to } 74 \text { years } \\
\text { Arthroscopic surgery } \\
\text { Major open surgery } \\
\text { (> } 45 \text { minutes) } \\
\text { Laparoscopic surgery } \\
\text { (> } 45 \text { minutes) } \\
\text { Malignancy } \\
\text { Confined to bed (> } 72 \text { hours) } \\
\text { Immobilizing plaster cast } \\
\text { Central venous access }\end{array}$ & $\begin{array}{l}\text { Age } \geq 75 \text { years } \\
\text { History of VTE } \\
\text { Family history of VTE } \\
\text { Factor V Leiden } \\
\text { Prothrombin } 20210 \mathrm{~A} \text { variant } \\
\text { Lupus anticoagulant } \\
\text { Anticardiolipin antibodies } \\
\text { Anti- } \beta 2 \text {-GPI antibodies } \\
\text { Elevated serum homocysteine } \\
\text { Heparin-induced thrombocy- } \\
\text { topenia } \\
\text { Other congenital or acquired } \\
\text { thrombophilia }\end{array}$ & $\begin{array}{l}\text { Stroke (< I month) } \\
\text { Elective arthroplasty } \\
\text { Hip, pelvis, or leg fracture } \\
\text { Acute spinal cord injury } \\
\text { (< I month) }\end{array}$ \\
\hline
\end{tabular}

BMI — body mass index; GPI — glycoprotein I; VTE — venous thromboembolism.

Score interpretation: 0 - very low risk, $1-2$ - low risk, $3-4-$ moderate risk; $\geq 5-$ high risk

Table 2. Definitions of risk categories

\begin{tabular}{|c|c|c|c|}
\hline Risk category & Incidence of distal DVT (\%) & Incidence of proximal DVT (\%) & Incidence of fatal PE (\%) \\
\hline High & $40-80$ & $10-30$ & $>1$ \\
\hline Moderate & $10-40$ & $1-10$ & $0.1-1$ \\
\hline Low & $<10$ & $<1$ & $<0.1$ \\
\hline
\end{tabular}

Risk category is related to the incidence of deep venous thrombosis (DVT) and fatal pulmonary embolism (PE) in different clinical situations. Individual risk estimation in each patient is the optimal approach

of thromboprophylaxis in this patient group. Based on the risk-to-benefit ratio, suggested measures in this patient group include early postoperative ambulation and mechanical methods of thromboprophylaxis (class $B$ recommendation). In patients with a very low procedure-related VTE risk (Caprini score 0), no data are available to support other measures than early postoperative ambulation (class $C$ recommendation).

In the moderate risk group (Caprini score 3-4, for examples of clinical conditions see Tables 2 and 3 ), it is recommended to use low-molecular-weight heparins (LMWH) (treatment initiation and dosing as recommended by the manufacturer) (class $\mathrm{A}$ recommendation) or unfractionated heparin (UFH) 5000 international units (IU) two or three times daily, initiated before the surgery (class $A$ recommendation). In patients with active bleeding or at high risk of bleeding, mechanical methods of thromboprophylaxis are recommended, including intermittent pneumatic compression (IPC) (the preferred method) and/or graduated compression stockings (GCS). Their use is recommended at least until the patient is ambulatory, and in patients immobilized for a longer time, at least until it becomes possible to initiate pharmacological thromboprophylaxis (class B recommendation).

A high VTE risk (Caprini score $\geq 5$ ) is present, among others, in patients $>40$ years of age undergoing major surgery with concomitant risk factors including malignancy (for detailed information about risk see Table 3). In the high VTE risk group, it is recommended to use LMWH (treatment initiation and dosing as recommended by the manufacturer - thromboprophylaxis should 
Table 3. Risk categories in relation to clinical risk factors in non-orthopedic surgical patients

\begin{tabular}{|c|c|c|c|}
\hline Risk category & General surgery & Gynecology & Obstetrics* \\
\hline \multirow[t]{3}{*}{ High } & $\begin{array}{l}\text { Major general surgery, } \\
\text { age }>60 \text { years }\end{array}$ & $\begin{array}{l}\text { Major gynecological surgery, } \\
\text { age }>60 \text { years }\end{array}$ & History of DVT/PE \\
\hline & $\begin{array}{l}\text { Major general surgery, } \\
\text { age } 40-60 \text { years and malignancy } \\
\text { or history of DVT/PE }\end{array}$ & $\begin{array}{l}\text { Major gynecological surgery, } \\
\text { age } 40-60 \text { years and malignancy } \\
\text { or history of DVT/PE }\end{array}$ & Trombophilia \\
\hline & Trombophilia & Trombophilia & \\
\hline \multirow[t]{3}{*}{ Moderate } & $\begin{array}{l}\text { Major general surgery, age } 40-60 \\
\text { years without other risk factors** }\end{array}$ & $\begin{array}{l}\text { Major gynecological surgery, } \\
\text { age } 40-60 \text { years }\end{array}$ & $\begin{array}{l}\text { Age }>35 \text { years, cesarean } \\
\text { section, obesity }\end{array}$ \\
\hline & Minor surgery, age $>60$ years & Minor surgery, age $>60$ years & \\
\hline & $\begin{array}{l}\text { Minor surgery, age } 40-60 \text { years } \\
\text { and history of DVT/PE or estrogen } \\
\text { therapy }\end{array}$ & $\begin{array}{l}\text { Major gynecological surgery, } \\
\text { age }<40 \text { years and estrogen } \\
\text { therapy }\end{array}$ & \\
\hline \multirow[t]{2}{*}{ Low } & $\begin{array}{l}\text { Major general surgery, age }<40 \\
\text { years without other risk factors* } *\end{array}$ & $\begin{array}{l}\text { Minor gynecological surgery, } \\
\text { age }<40 \text { years without other } \\
\text { risk factors } * *\end{array}$ & $\begin{array}{l}\text { Age }<35 \text { years without other } \\
\text { risk factors }\end{array}$ \\
\hline & $\begin{array}{l}\text { Minor surgery, age } 40-60 \text { years } \\
\text { without other risk factors** }\end{array}$ & $\begin{array}{l}\text { Minor gynecological surgery, age } \\
40-60 \text { years without other risk } \\
\text { factors** }\end{array}$ & \\
\hline
\end{tabular}

DVT — deep vein thrombosis; PE — pulmonary embolism

*Risk of DVT in pregnant women with preeclampsia and other risk factors is not known but prophylaxis should be considered

**Risk is increased by infectious diseases, varicose veins, and immobilization. Minor surgery is defined as not involving the abdominal cavity and lasting shorter than 45 minutes. Major surgery is defined as involving the abdominal cavity or lasting longer than $\mathbf{4 5}$ minutes

be initiated before the procedure) (class A recommendation) or UFH (5000 IU, first dose 2 hours before the surgery, followed by three times daily) (class A recommendation). LMWH are preferred as these drugs are administered once daily and the risk of heparin-induced trombocytopenia (HIT) is lower compared to UFH. An alternative approach is to use fondaparinux (initiation of thromboprophylaxis after the procedure) (class $B$ recommendation).

To increase the effectiveness of thromboprophylaxis in patients at high or very high VTE risk, it is suggested to combine pharmacological thromboprophylaxis with mechanical methods (IPC or GCS, optimally IPC). Use of mechanical thromboprophylaxis (preferred IPC) is also justified in patients with active bleeding or contraindications to pharmacological thromboprophylaxis - at least until it becomes possible to administer anticoagulants (class $\mathrm{C}$ recommendation).

Due to an increased VTE risk in the postoperative period - also after hospital discharge — the authors of PCS 2017 recommend extending primary thromboprophylaxis to 28 days in patients after major abdominal and pelvic surgery, including major abdominal and pelvic procedures for malignancy (class B recommendation).

In patients undergoing minimally invasive procedures, including laparoscopic procedures, VTE risk needs to be assessed individually and thromboprophylaxis tailored to the risk should be initiated. In patients at low VTE risk undergoing short laparoscopic procedures, the authors of PCS 2017 do not recommend routine pharmacological thromboprophylaxis and recommend use of mechanical methods including early ambulation, GCS, or IPC (preferred) (class C recommendation).

Prolonged laparoscopic surgery using pneumoperitoneum results in a reduction of lower limb venous outflow. Due to lack of studies that would provide adequate quality data on such procedures, it is suggested that in patients undergoing prolonged laparoscopic procedures, oncological laparoscopic procedures, and extensive laparoscopic procedures within the abdominal cavity and particularly within the pelvis, pharmacological thromboprophylaxis should be used as in open surgery (class $C$ recommendation). Regarding VTE risk, the authors of PCS 2017 believe that periodic decompression of pneumoperitoneum and consideration of mechanical methods of thromboprophylaxis, particularly IPC (class C recommendation), are important prevention measures in this patient group.

\section{Vascular surgery}

Despite intraoperative UFH administration and use of other anticoagulants in the perioperative period, patients undergoing vascular surgery are at risk of thromboembolic complications. Few studies that were performed in small patient groups did not allow the VTE prevention algorithm to be clearly established in this patient population. Important issues related to defining the 
approach to VTE prevention in vascular surgery include varying duration of procedures (including intravascular procedures) and frequent use of antiplatelet drugs that increase the risk of bleeding complications.

It seems that VTE incidence is higher in case of extensive reconstructive surgery, in particular in patients undergoing open reconstructive surgery involving the aorta or the aortoiliac segment. Specific risk factors affecting the incidence of VTE complications in vascular surgery patients include advanced age, severe (including critical) limb ischemia, prolonged surgery, local trauma related to extensive vascular reconstructive surgery, possible venous damage, and chronic immobilization related to lower limb amputation. Due to immobilization in the perioperative period, other VTE risk factors are also important as in general surgical patients.

\section{Recommendations}

An individual assessment of the risk of VTE and bleeding complications is recommended in patients undergoing vascular surgery procedures (class A recommendation). It is not recommended to use routine pharmacological thromboprophylaxis in all patients undergoing diagnostic and therapeutic vascular procedures (class $C$ recommendation). Pharmacological thromboprophylaxis with LMWH or UFH is suggested in all patients undergoing vascular reconstructive surgery in whom VTE risk factors are present and the risk is bleeding complications is not excessively increased (class $\mathrm{C}$ recommendation). In other patients without additional risk factors, the decision to initiate thromboprophylaxis should be made individually, taking into account perioperative anticoagulation, duration of the immobilization period, postoperative recovery, the extent of the procedure, and the risk of bleeding complications (class $\mathrm{Cl}$ recommendation).

\section{Urologic surgery}

Symptomatic VTE develops in $1-5 \%$ patients undergoing extensive urologic procedures. The risk of VTE in case of extensive open urologic surgery is similar to that noted in extensive open general surgical procedures. In addition to malignancies which are often the indication for surgery, other significant risk factors in patients undergoing urologic surgery include advanced age, extensive pelvic surgery often associated with extensive retroperitoneal lymph node resection, lithotomy position of the patient, and hormonal therapy (e.g. using antiandrogens). Considering the age of this patient population, common concomitant conditions and other VTE risk factors should be also taken into account.

An increasing number of urologic procedures are performed using minimally invasive techniques (lapa- roscopic and endoscopic). These procedures are also associated with thromboembolic complications. The incidence of VTE following laparoscopic urologic procedures has been estimated at $0.13-4.8 \%$, and in case of endoscopic procedures, the incidence of symptomatic DVT has been estimated at $0.1-0.75 \%$, and of PE at $0.1-0.84 \%$. This risk is significantly increased if malignancy is present. Specific characteristics of urologic procedures, including a large proportion of endoscopic procedures and a potential risk of bleeding associated with procedures involving the urinary tracts, warrant consideration of these factors and an individualized approach in patients undergoing oncologic procedures.

\section{Recommendations}

An individual assessment of the risk of VTE and bleeding complications is recommended in patients undergoing oncological urologic procedures (class A recommendation). In patients undergoing extensive open urologic procedures, we recommend pharmacological thromboprophylaxis with low UFH doses (class A recommendation) or prophylactic $\mathrm{LMWH}$ doses - as in high risk patients (class $C$ recommendation). In the remaining urologic patients undergoing surgical procedures other than extensive open urologic procedures, in whom VTE risk is high or moderate and the bleeding risk is not high, we suggest thromboprophylaxis with UFH or LMWH (with dosing as recommended by the manufacturer) (class $C$ recommendation). Due to specific characteristics of this patient population and procedures performed, the optimal timing of initiation of pharmacological thromboprophylaxis should depend on the individual assessment of the risk-to-benefit ratio associated with pharmacological thromboprophylaxis. In case of a significant bleeding risk in the perioperative period, we suggest using mechanical methods of thromboprophylaxis (IPC preferred) and initiation of pharmacological thromboprophylaxis when it becomes feasible following reduction of the bleeding risk (class $C$ recommendation).

Use of mechanical methods (IPC preferred) is also suggested in addition to pharmacological thromboprophylaxis to increase its effectiveness in patients at high or very high VTE risk (class $C$ recommendation).

In patients undergoing percutaneous and endoscopic procedures associated with a low VTE risk, we recommend early ambulation and use of mechanical methods of thromboprophylaxis (class $\mathrm{C}$ recommendation). If additional VTE risk factors are present in this patient group, initiation of pharmacological thromboprophylaxis with UFH or LMWH should be considered (class $\mathrm{Cl}$ recommendation). In patient at high VTE risk and high bleeding risk undergoing endoscopic procedures, we suggest initiation of mechanical methods of throm- 
boprophylaxis first (IPC preferred) and initiation of pharmacological thromboprophylaxis after adequate hemostasis is achieved.

\section{Plastic surgery}

Occurrence of VTE following plastic surgery procedures requires further research. Due to varying extent of the procedures and patient age, different VTE risk factors and their rates, and varying bleeding risk in different patient groups, no clinical trials are available to clearly define the approach to thromboprophylaxis in this patient population. Due to lack of adequately designed and conducted clinical trials, VTE prevention in plastic surgery patients should follow the approach established for general surgical patients and involve risk stratification based on an individual assessment of the risk of thrombosis and bleeding complications in each patient.

\section{Recommendations}

An individual assessment of the risk of VTE and bleeding complications is recommended in patients undergoing plastic surgery procedures (class $A$ recommendation). In patients at low VTE risk, we recommend early ambulation and use of mechanical methods of thromboprophylaxis including GCS and/or IPC (class CI recommendation). In patients at moderate or high VTE risk, we suggest pharmacological thromboprophylaxis with low doses of UFH or LMWH if this approach is not associated with a high risk of bleeding complications in a given clinical scenario (class $\mathrm{Cl}$ recommendation). To increase the effectiveness of thromboprophylaxis in high risk patients and those with contraindications to pharmacological thromboprophylaxis (e.g., due to high bleeding risk), we recommend use of mechanical methods of thromboprophylaxis including (GCS or IPC, optimally IPC) (class $\mathrm{Cl}$ recommendation). In patients at high VTE risk and high bleeding risk in whom use of pharmacological thromboprophylaxis is associated with concerns regarding increased local bleeding, we suggest individual decisions regarding the timing of the initiation of pharmacological thromboprophylaxis - until adequate hemostasis is achieved that allows initiation of pharmacological thromboprophylaxis, use of mechanical methods (optimally IPC) is recommended in such cases (class $\mathrm{Cl}$ recommendation).

\section{Neurosurgery}

If no thromboprophylaxis is used in patients undergoing neurosurgical procedures, the incidence of asymptomatic DVT detected using fibrinogen scintigraphy is about $22 \%$, and proximal DVT is detected in $5 \%$ of patients. In studies that evaluated the risk of VTE in patients undergoing craniotomy due to malignancy without any thromboprophylaxis, the incidence of VTE was at least $10 \%$ and was particularly high in patients with glioma $(2 \mathrm{I}-32 \%$, with the rate of symptomatic postoperative DVT of $3-25 \%)$. In addition to the presence of malignancy, other factors associated with the risk of VTE in patients undergoing neurosurgical procedures include the type and severity of malignancy, non-radical tumor excision, prolonged surgery, limb paralysis, and prolonged postoperative immobilization. Due to specific characteristics of the neurosurgical patient population, the risk of bleeding complications associated with neurosurgical procedures and the effect of pharmacological thromboprophylaxis on their occurrence should also be taken into account in addition to the assessment of VTE risk.

\section{Recommendations}

An individual assessment of the risk of VTE and bleeding complications is recommended in patients undergoing neurosurgical procedures (class $A$ recommendation). Due to the risk of bleeding complications, we recommend use of mechanical methods of thromboprophylaxis (optimally IPC) in the perioperative period in patients undergoing neurosurgical procedures (class $\mathrm{C}$ recommendation). In patients undergoing neurosurgical procedures in whom VTE risk is high and the bleeding risk is not high, we suggest supplementing mechanical methods with pharmacological thromboprophylaxis using low UFH or LMWH doses in the postoperative period (class $\mathrm{C}$ recommendation). The timing of initiation of pharmacological thromboprophylaxis should be determined individually, taking into account the risk of bleeding complications and the degree of hemostasis (class $\mathrm{C}$ recommendation).

\section{Thoracic surgery}

Thoracic surgery procedures are associated with a significant risk of thromboembolic complications in the postoperative period. This risk is particularly high in patients operated due to a malignancy, and increases even higher in case of extensive surgery due to lung malignancy. Methodologically limited data are available on thromboprophylaxis in patients undergoing thoracic surgery procedures, and recommendations for this patient group are mostly based on extrapolation of recommendations developed for general surgical patients (with consideration of the bleeding risk associated with thoracic surgery procedures). No adequate quality data are also available on thromboprophylaxis in patients undergoing thoracoscopic procedures.

\section{Recommendations}

An individual assessment of the risk of VTE and bleeding complications is recommended in patients 
undergoing thoracic surgery procedures (class A recommendation). In patients undergoing thoracic surgery procedures in whom VTE risk is high and the procedure is not associated with a high bleeding risk, we suggest pharmacological thromboprophylaxis using LMWH or UFH (class $C$ recommendation). In patients at high VTE risk, we suggest supplementing pharmacological thromboprophylaxis with mechanical methods (optimally IPC) (class $C$ recommendation). In patients undergoing thoracic surgery procedures associated with high VTE risk in whom the bleeding risk is high, we suggest mechanical methods (optimally IPC), at least until the bleeding risk decreases and pharmacological thromboprophylaxis becomes feasible (class $\mathrm{C}$ recommendation). In case of thoracoscopic procedures, we suggest individual assessment of the risk-to-benefit ratio associated with pharmacological thromboprophylaxis based on individual VTE risk and the bleeding risk related to the procedure. In this patient group, we suggest early ambulation and use of mechanical methods, and in patients at an increased VTE risk also pharmacological thromboprophylaxis if the procedure is not associated with a high bleeding risk.

\section{Gynecology}

Thromboembolic complications following gynecological surgery occur at more or less the same rate as following general surgical procedures [4, 5]. In patients aged 40 years and above undergoing major gynecological procedures (e.g., lasting more than 30 minutes), VTE risk in the postoperative period is significant and increases further if additional risk factors are present, such as obesity, previous VTE, malignancy, chemotherapy, or immobilization. It seems, however, that VTE occurs at a much lower rate if the surgery is not due to a malignancy or is limited to the vagina. $\mathrm{PE}$ is the most common cause of clinical deterioration and mortality following gynecological surgery. Without thromboprophylaxis, the incidence of DVT following extensive gynecological surgery is 15-40\%.

Risk factors for VTE are similar to general surgery. Additional VTE risk is associated with the use of estrogen-containing combined oral contraceptives. Oral contraceptive pills increase the risk of VTE. However, the absolute risk is small, increasing from 5 to $15-30$ per 100,000 patient-years. The latter risk is smaller than the risk associated with pregnancy, estimated at 100 per 100,000 pregnancies. In early studies, an increase in VTE risk in the postoperative period was observed, from $0.5 \%$ in women who did not use oral contraceptives to $1 \%$ among those who used oral contraceptives. This absolute increase in risk in women using oral contraceptives must be balanced with the risk of stopping these medications 4-6 weeks before the surgery. Each case should be judged individually, taking into account additional risk factors. Oral contraceptives should be withdrawn at least 4 weeks before a major surgery. If a decision is made not to stop oral contraception, the patient should be offered thromboprophylaxis as in the moderate risk group. Other estrogen-containing preparations should be considered associated with the same risk as oral contraconceptives, at least until appropriate studies are performed. In case of an urgent surgery, thromboprophylaxis should be used as in the moderate risk group. Oral contraconception needs not to be interrupted in case of minor procedures that are not associated with patient immobilization. Progestin-only contraceptives also do not need to be interrupted even if the patient is expected to be immobilized.

When evaluating patients before elective or urgent surgery, hormone replacement therapy (HRT) should be considered a risk factor for VTE. There is no need for routine interruption of HRT before the surgery if appropriate thromboprophylaxis is used, e.g., using UFH or LMWH. Transdermal HRT seems to have a lesser effect on coagulation and is associated with a lower risk of VTE compared to oral HRT.

\section{Recommendations}

Measures used in low risk patients include GCS, early ambulation, and adequate hydration (class B recommendation). In moderate and high risk patients, $\mathrm{LMWH}$ (treatment initiation and dosing as recommended by the drug manufacturer), UFH (5000 IU every 8 or 12 hours), or IPC should be used (class A recommendations). LMWH are preferred as these drugs are administered once daily and the risk of HIT is lower. IPC is the method of choice in patients at high bleeding risk.

In the highest risk patients, we recommend $\mathrm{LMWH}$ (treatment initiation and dosing as recommended by the drug manufacturer) (class $A$ recommendation), UFH (5000 IU every 8 hours) (class A recommendation), or IPC. Pharmacological thromboprophylaxis should be used throughout the hospital stay, and in some situations for up to 4 weeks after hospital discharge (class B recommendation). Optimal VTE prevention is provided by a combination of LMWH or UFH with IPC or GCS (class $B$ recommendation).

Fondaparinux is used in women with HIT or a history of allergy to $\mathrm{LMWH}$.

\section{Obstetrics}

Pregnancy is a risk factor for VTE: its incidence during pregnancy is increased 5- to 10 -fold compared to non-pregnant women of comparable age. Forty percent of VTE events occur in the first trimester, particularly following in vitro fertilization. The risk is highest in the postpartum period. PE remains the major direct cause 
of mortality during pregnancy and the postpartum period. Additional VTE risk factors during pregnancy and the postpartum period include age above 35 years, thrombophilia, diabetes, hypertension, cesarean section, surgery during pregnancy, and obesity. Evaluation of VTE risk is recommended in all women during early pregnancy. Of note, uncomplicated pregnancy is also an independent risk factor for VTE [6-I I].

Table 4 shows the recommended management strategies in various obstetrical clinical scenarios.

\section{Recommendations}

Women at high VTE risk, including patients with a history of documented VTE, should be offered preconception counselling to develop an agreed management plan. Thrombotic risk increases already in early pregnancy.

Screening for inherited and acquired thrombophilias should be performed before pregnancy in women with a personal or family history of VTE (class C recommendation). Risk factors for VTE should be evaluated in all women before pregnancy or in early pregnancy. This assessment should be repeated if a woman is admitted due to pregnancy complications that require bedrest, such as hyperemesis gravidarum, preeclampsia, or vaginal bleeding (class $C$ recommendation).

The authors of systematic reviews and retrospective studies concluded that based on effectiveness and safety, the treatment of choice in pregnant women is $\mathrm{LMWH}$ and not UFH (class $B$ recommendation). Compared to UFH, use of LMWH is associated with a lower risk of HIF and osteoporosis during pregnancy. If HIT develops during pregnancy, fondaparinux is the drug of choice in Polish practice settings. Fondaparinux may also be used in case of allergy to LMWH.

The overall risk of DVT recurrence during pregnancy has been estimated at 2-3\%, higher in patients with thrombophilia or previous idiopathic thrombosis (6\%). In women with a history of VTE event associated with a temporary risk factor that is no longer present, without established thrombophilia or additional risk factors, thromboprophylaxis using LMWH should be used only in the postpartum period (class $C$ recommendation). In addition, use of GCS may be considered during pregnancy (class $C$ recommendation).

In women with a history of VTE event associated with previous pregnancy or use of estrogen-containing hormonal therapy (including combined oral contraceptives), or with additional risk factors such as obesity, thromboprophylaxis using LMWH should be initiated as early as possible during pregnancy and continued until 6 weeks after the delivery (class $C$ recommendation).

In women with thrombophilias, VTE risk during pregnancy is increased and depends on the type of thrombophilia. In patients with thrombophilia and a history of VTE, thromboprophylaxis using LMWH should be used throughout pregnancy and for 6 weeks after the delivery (class $B$ recommendation).

In case of extended secondary VTE prevention and in women with antithrombin deficiency, the risk of VTE during pregnancy is very high (30\%). Due to the risk of warfarin-induced embryopathy between 6 and 12 weeks of gestation, patients receiving vitamin $\mathrm{K}$ antagonists (VKA) should be advised to switch this therapy to LMWH immediately after pregnancy is confirmed. In both these situations, LMWH dose should be similar to the dose used for the treatment of VTE (class B recommendation).

Table 5 shows recommendation on LMWH dosing during pregnancy developed in the United Kingdom by the Royal College of Obstetricians and Gynecologists.

Note: Unlike in the United Kingdom, three LMWH preparations are available in Poland, including dalteparin, enoxaparin, and nadroparin.

Novel oral anticoagulants, including direct thrombin inhibitors (dabigatran) and factor $\mathrm{Xa}$ inhibitors (apixaban, edoxaban, rivaroxaban) are contraindicated during both pregnancy and lactation.

Women with a history of VTE with established thrombophilia, such as protein $C$ deficiency, factor $V$ Leiden mutation, prothrombin 20210A variant, or protein S deficiency, in whom VTE risk is increased, should receive LMWH (e.g., enoxaparin $40 \mathrm{mg}$ daily or dalteparin 5000 units daily in women of normal body weight) since early pregnancy (class $C$ recommendation).

Women with established thrombophilia but no history of venous thrombosis may also require thromboprophylaxis (depending on the type of thrombophilia, family history, and the presence of additional risk factors, such as immobilization, hyperemesis gravidarum, or obesity). In women with these risk conditions thromboprophylaxis should be used after delivery. Before delivery, the risk of thrombosis should be discussed with the patient and use of GCS should be considered (class $\mathrm{C}$ recommendation). In case of antithrombin deficiency, thromboprophylaxis is recommended since the diagnosis of pregnancy (class $C$ recommendation).

In patients with antiphospholipid syndrome and recurrent miscarriage but no history of a VTE event, thromboprophylaxis using $\mathrm{LMWH}$ and low doses of acetylsalicylic acid (75-100 mg daily) should be used since the diagnosis of pregnancy (class A recommendation). The aim of this treatment is to prevent pregnancy loss due to placental vessel thrombosis. Those patients are also at risk of VTE and thus thromboprophylaxis using LMWH should be continued also after delivery. In patients with antiphospholipid syndrome and a his- 
Table 4. Recommended management approaches in various clinical scenarios

\begin{tabular}{|c|c|}
\hline Clinical scenario & Recommended management \\
\hline $\begin{array}{l}\text { Single previous VTE event (not asso- } \\
\text { ciated with pregnancy or oral contra- } \\
\text { ception) associated with a transient risk } \\
\text { factor, currently without additional risk } \\
\text { factors }\end{array}$ & $\begin{array}{l}\text { Before delivery: } \\
\text { - Surveillance or prophylactic LMWH dose } \pm \text { GCS } \\
\text { - Discussion of issues related to LMWH use with the patient, such as obesity } \\
\text { before delivery } \\
\text { After delivery: } \\
\text { - Anticoagulation for at least } 6 \text { weeks } \pm \text { GCS }\end{array}$ \\
\hline $\begin{array}{l}\text { Single previous VTE event - idiopathic, } \\
\text { associated with pregnancy or estrogen- } \\
\text { containing combined oral contraception, } \\
\text { or due to thrombophilia in a patient not } \\
\text { receiving chronic anticoagulant treat- } \\
\text { ment }\end{array}$ & $\begin{array}{l}\text { Before delivery: } \\
\text { — Prophylactic LMWH dose } \pm \text { GCS } \\
\text { — Very reliable data suggest more intensive LMWH treatment in case of antithrom- } \\
\text { bin deficiency } \\
\text { After delivery: } \\
\text { — Anticoagulation for at least } 6 \text { weeks } \pm \text { GCS (e.g., pathological obesity, nephrotic } \\
\text { syndrome) }\end{array}$ \\
\hline $\begin{array}{l}\text { At least one previous VTE event without } \\
\text { thrombophilia in a patient not on chronic } \\
\text { anticoagulation or single previous VTE } \\
\text { event with currently present additional } \\
\text { risk factors }\end{array}$ & $\begin{array}{l}\text { Before delivery: } \\
\text { - Prophylactic LMWH dose + GCS } \\
\text { After delivery: } \\
\text { - Anticoagulation for at least } 6 \text { weeks + GCS }\end{array}$ \\
\hline $\begin{array}{l}\text { At least one previous VTE event in } \\
\text { a patient on chronic anticoagulation } \\
\text { (e.g., with thrombophilia) }\end{array}$ & $\begin{array}{l}\text { Before delivery: } \\
\text { - Switch of oral anticoagulation to therapeutic LMWH dose before } 6 \text { weeks of } \\
\text { gestation + GCS } \\
\text { After delivery: } \\
\text { - Return to chronic oral anticoagulation with continuation of LMWH until } \\
\text { therapeutic INR values as before pregnancy + GCS }\end{array}$ \\
\hline Thrombophilia without previous VTE & $\begin{array}{l}\text { - Indications for LMWH use before delivery are stronger in women with anti- } \\
\text { thrombin deficiency than in women with other thrombophilias, in case of clinical } \\
\text { symptoms in family members compared to asymptomatic family members, and } \\
\text { with concomitant additional risk factors } \\
\text { After delivery: } \\
\text { - Anticoagulation for at least } 6 \text { weeks } \pm \text { GCS }\end{array}$ \\
\hline Following cesarean section & $\begin{array}{l}\text { Evaluation of VTE risk - thromboprophylaxis should be used at least until } \\
\text { hospital discharge* if other risk factors are present, such as urgent cesarean section } \\
\text { performed after initiation of labor, age }>35 \text { years, high BMl etc. }\end{array}$ \\
\hline Following vaginal delivery & $\begin{array}{l}\text { Evaluation of VTE risk — thromboprophylaxis } \pm \text { GCS should be considered at least } \\
\text { until hospital discharge* if at least } 2 \text { additional risk factors are present, such as age } \\
>35 \text { years, high BMl etc. }\end{array}$ \\
\hline
\end{tabular}

VTE — venous thromboembolism; LMWH — low-molecular-weight heparin; GCS — graduated compression stockings; INR — international normalized ratio; $\mathrm{BMI}$ - body mass index

*Consider extended thromboprophylaxis following hospital discharge if multiple risk factors are present

Table 5. Recommendations on prophylactic and therapeutic low-molecular weight heparin doses before delivery (developed by RCOG)

\begin{tabular}{|l|l|l|}
\hline Prophylaxis & Enoxaparin & 5000 units daily \\
\hline Normal body weight & $40 \mathrm{mg}$ daily & 2500 units daily \\
Body weight $<50 \mathrm{~kg}$ & $20 \mathrm{mg}$ daily & 5000 units every I2 hours \\
Body weight $>90 \mathrm{~kg}$ & $40 \mathrm{mg}$ every I 2 hours & 90 units/kg every I2 hours \\
Therapeutic dose & $\mathrm{I} \mathrm{mg/kg} \mathrm{every} \mathrm{I2} \mathrm{hours}$ & \\
\hline
\end{tabular}


tory of VTE event, thus thromboprophylaxis should be continued for at least 6 weeks after delivery (class C recommendation).

In women who received LMWH before delivery and wish to deliver with epidural anesthesia, epidural puncture during delivery should be performed at least I 2 hours after administration of a prophylactic LMWH dose and 24 hours after administration of a therapeutic LMWH dose. LMWH may not be administered during at least 4 hours after epidural anesthesia catheter insertion or removal, and the catheter may not be removed during $10-12$ hours since last LMWH dose injection. If delivery is by elective cesarean section, the patient should receive a prophylactic LMWH dose on the day before delivery. On the day of delivery, a prophylactic LMWH dose is administered 3 hours after cesarean section or 4 hours after an epidural anesthesia catheter is removed (class $C$ recommendation).

When considering thromboprophylaxis during the postpartum period, other risk factors in addition to previous VTE and thrombophilia should also be taken into account, including age above 35 years, obesity, cesarean section (particularly if performed urgently after initiation of labor), large varicose veins, preeclampsia, and immobilization (class $C$ recommendation).

Thromboprophylaxis in the postpartum period is recommended in women with a history of VTE, with established thrombophilia, and with other risk factors for thrombosis. The initial daily LMWH dose in this period (40 mg of enoxaparin, 5000 units of dalteparin) should be administered 3-4 hours after delivery. In patients with a history of VTE or with established thrombophilia, thromboprophylaxis should be continued for at least 6 weeks after delivery. In other women, thromboprophylaxis is continued until hospital discharge, and the need for thromboprophylaxis should be reconsidered if the duration of hospital stay exceeds 5 days (class B recommendation).

If the patient is not willing to perform self-injections and breastfeeds on the first or second day after delivery, VKA may be initiated. LMWH administration may be then terminated if the international normalized ratio (INR) is within the target range (i.e., 2-3) for two subsequent days. In high risk patients, combined thromboprophylaxis with LWMH and GCS may be used, and the latter method is chosen if LMWH is contraindicated.

If anticoagulants are contraindicated, GCS should be used for at least 6 weeks after delivery, and this method may be combined with administration of acetylsalicylic acid $75 \mathrm{mg}$ per day (class $C$ recommendation).

Investigations for thrombophilia should be performed in women who develop VTE during pregnancy or the postpartum period.
Counselling regarding an increased VTE risk associated with the use of estrogen-containing combined oral contraceptives is also indicated in all women.

Breastfeeding is not contraindicated during $\mathrm{LWMH}$, UFH, and VKA use. Novel oral anticoagulants and fondaparinux are contraindicated during the breastfeeding period (class $C$ recommendation).

\section{Orthopedic surgery and traumatology Trauma}

Detailed recommendations regarding VTE prevention in orthopedic surgery and traumatology have been developed by Polish orthopedic surgery experts under the auspices of the national consultant for orthopedic surgery and traumatology and the chairman of the Polish Society for Orthopedic Surgery and Traumatology and published in the Ortopedia, Traumatologia, Rehabilitacja journal (2014; 16: 227-239) — an update dated Feb 18,2014 [12].

\section{Total hip replacement}

Without thromboprophylaxis, the risk of DVT in patients undergoing elective major joint replacement and those with hip fracture is about $50 \%$. The incidence of proximal DVT and PE is also high. The rate of symptomatic events is $2-5 \%$. Studies on symptomatic DVT and PE indicate that an increased risk in the postoperative period persists for about 3 months. Recent studies have confirmed an increased mortality during 2-3 months following elective total hip replacement (THR), with the highest death rates in the earliest period after the surgery.

Currently, the duration of hospital stay following THR continues to be reduced (3-6 days), and thus patients are discharged during the period of an increased risk. Most clinical events occur after hospital discharge, leading to a false impression that this problem is of a lesser importance now.

\section{Recommendations}

Class A recommendations include administration of LMWH (treatment initiation and dosing as recommended by the manufacturer), apixaban, dabigatran, fondaparinux (may be used in patients with HIT), rivaroxaban, and IPC or foot impulse technology (FIT) combined with GCS. Use of IPC or FIT with GCS is an approach alternative to LMWH administration in patients at high perioperative bleeding risk. Mechanical methods may be used for as long as it is tolerated by the patient, followed by pharmacological thromboprophylaxis for the rest of the 5-week risk period. VKA use is associated with an increased rate of major bleeding complications and is not 
recommended by the authors of PCS 2017 (class $\mathrm{CI}$ recommendation).

Thromboprophylaxis using LMWH may be initiated before or after the surgery depending on the management approach (class $A$ recommendation). Administration of fondaparinux (class $A$ recommendation) should be initiated earliest at 6-8 hours after the surgery. Apixaban (class A recommendation) should be initiated 12-24 hours after the surgery, dabigatran (class A recommendation) should be initiated $\mathrm{I}-4$ hours after the surgery, and rivaroxaban (class $A$ recommendation) should be initiated 6-10 hours after the surgery. Thromboprophylaxis should be continued for 35 days after the surgery (class $B$ recommendation) when using either LMWH, apixaban (for 32-38 days as stated in the SPC), dabigatran (28-35 days as stated in the SPC), rivaroxaban (class $A$ recommendation for all drugs listed), and fondaparinux ( 35 days as stated in the SPC).

Continuation of antiplatelet therapy using acetylsalicylic acid ( $<325 \mathrm{mg}$ per day) is recommended in patients at high risk of arterial thromboembolic events (class $\mathrm{C}$ recommendation).

\section{Elective total knee replacement}

A high rate of proximal DVT (18-36\%) is observed in patients undergoing THR, in contrast to patients undergoing total knee replacement (TKR) in whom thrombosis develops more distally.

\section{Recommendations}

Class $\mathrm{A}$ recommendations include administration of LMWH (treatment initiation and dosing as recommended by the manufacturer), apixaban, dabigatran, fondaparinux (may be used in patients with HIT), rivaroxaban, and IPC or FIT combined with GCS. Use of IPC or FIT with GCS is an approach alternative to LMWH administration in patients at high perioperative bleeding risk. Mechanical methods may be used for as long as it is tolerated by the patient, followed by pharmacological thromboprophylaxis for the rest of the 2-week risk period. VKA use is associated with an increased rate of major bleeding complications and is not recommended by the authors of PCS 2017 (class $\mathrm{Cl}$ recommendation).

Thromboprophylaxis using LMWH may be initiated before or after the surgery depending on the management approach (class $A$ recommendation). Administration of fondaparinux (class $A$ recommendation) should be initiated earliest at 6-8 hours after the surgery. Apixaban (class $A$ recommendation) should be initiated 12-24 hours after the surgery, dabigatran (class $A$ recommendation) should be initiated $\mathrm{I}-4$ hours after the surgery, and rivaroxaban (class $A$ recommendation) should be initiated 6-10 hours after the surgery. Thromboprophylaxis should be continued for 14 days after the surgery (class $B$ recommendation) when using either LMWH, apixaban (for 10-14 days as stated in the SPC), dabigatran ( 10 days as stated in the SPC), rivaroxaban ( 14 days as stated in the SPC) (class A recommendation for all drugs listed), and fondaparinux (class A recommendation).

Continuation of antiplatelet therapy using acetylsalicylic acid (< $325 \mathrm{mg}$ per day) is recommended in patients at high risk of arterial thromboembolic events (class $\mathrm{C}$ recommendation).

\section{Hip fracture}

Patients operated due to hip fracture are characterized by the highest rate of DVT (46-60\%) and fatal PE (2.5-7.5\%). The period of an increased VTE risk persists for 2-3 months after the surgery despite frequent use of short-term thromboprophylaxis, and the overall 90 -day mortality risk is $13 \%$. Following hip fracture, the mortality risk is higher compared to standardized mortality in the general population, and most deaths are due to vascular events, although some form of short-term prophylaxis is used in most patients.

\section{Recommendations}

Class A recommendations include administration of LMWH (treatment initiation and dosing as recommended by the manufacturer), UFH in low doses, or fondaparinux (class $B$ recommendation). If pharmacological thromboprophylaxis is contraindicated, IPC or FIT combined with GCS should be used (class B recommendation). If delay in surgical treatment is likely, thromboprophylaxis using LMWH, IPC or FIT combined with GCS should be initiated as early as possible after fracture (class $C$ recommendation).

Continuation of antiplatelet therapy using acetylsalicylic acid (<325 $\mathrm{mg}$ per day) is recommended in patients at high risk of arterial thromboembolic events (class $\mathrm{C}$ recommendation).

In case of periprosthetic fractures around the knee, pharmacological thromboprophylaxis using LMWH or fondaparinux is recommended. Thromboprophylaxis should be initiated immediately after hospital admission and continued for at least 35 days or longer in case of long-term immobilization following the surgery or inadequate rehabilitation progress. If pharmacological thromboprophylaxis needs to be used for longer than 3 months, it is recommended to substitute VKA for LMWH or fondaparinux.

Lower limb arthroscopy and other minimally invasive (endoscopic) procedures within the lower limb

Knee arthroscopy is a common procedure of varying extent, from a simple diagnostic procedure to extensive repair of damaged soft tissues. A tourniquet is usually used. 
Without thromboprophylaxis, the overall incidence of DVT detected using routine venography or compression ultrasonography in patients undergoing arthroscopic procedures is about $7 \%$, and the rate of proximal DVT is $1.4 \%$. The risk associated with diagnostic arthroscopy is low but increases if the tourniquet if left in place for longer than an hour or a therapeutic arthroscopy is performed [13-18].

Symptomatic VTE may occur but is very rare following arthroscopy performed without thromboprophylaxis [14].

\section{Recommendations}

An individual assessment of the risk of thromboembolic and bleeding complications is recommended in all patients undergoing arthroscopy. Routine thromboprophylaxis is not recommended in patients with low individual VTE risk.

In case of arthroscopic surgical procedures (e.g., ligament reconstruction), administration of $\mathrm{LMWH}$ is recommended in patients at an increased VTE risk, initiated before or after the surgery (class $B$ recommendation) and continued for 8-10 days. If LWMH is contraindicated, IPC should be used (class $C$ recommendation).

\section{Lower limb fractures}

In immobilized patients with lower limb trauma, the incidence of DVT is $10-35 \%$ depending on the type and severity of trauma, and the risk of clinically overt

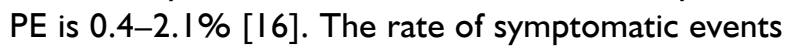
is not known.

Due to heterogeneity of this patient group, conducting adequate studies and developing recommendations is difficult [14].

\section{Recommendations}

The 2017 Polish Consensus Statement does not recommend routine thromboprophylaxis in patients with lower limb trauma treated with immobilization and plaster casts (class $C$ recommendation).

The 2017 Polish Consensus Statement recommends thromboprophylaxis only in patients at moderate and high VTE risk. LWMH should be administered in such patients in case of lower limb trauma if treated with immobilization and plaster casts (class $\mathrm{Cl}$ recommendation). Use of prophylactic LMWH doses is recommended for the duration of immobilization and 5-7 days afterwards (class $\mathrm{Cl}$ recommendation).

\section{Multiple trauma}

The incidence of DVT in patients with major trauma exceeds $50 \%$, and PE is the third most common cause of mortality in major trauma patients who survive more than one day. This risk is particularly high in patients with spinal cord trauma, pelvis fractures, and in patients who require surgical treatment.

\section{Recommendations}

In patients at an increased VTE risk, LMWH administration since the occurrence of trauma is recommended if the bleeding risk is not excessively high (class $A$ recommendation), and IPC should be used if $\mathrm{LMWH}$ is contraindicated (class $B$ recommendation). Thromboprophylaxis should be continued until the patient is fully ambulatory.

\section{Elective spine surgery}

Without thromboprophylaxis, the incidence of DVT detected by routine venography is $18 \%$. A review of studies on complications in patients undergoing surgical spondylodesis found that the rate of symptomatic DVT was $3.7 \%$, and the rate of PE was $2.2 \%$.

\section{Recommendations}

In patients at an increased VTE risk, we recommend considering thromboprophylaxis with mechanical methods (IPC) (class B recommendation) or LMWH (class $B$ recommendation). Thromboprophylaxis should be initiated before the surgery (if IPC is used) or after the surgery (if $\mathrm{LMWH}$ is used), already during the hospital stay (class $\mathrm{C}$ recommendation).

\section{Spinal cord trauma}

Without thromboprophylaxis, the incidence of clinically silent DVT is $35-90 \%$. In this patient group, PE is the third most common cause of mortality.

\section{Recommendations}

In patients at an increased VTE risk, we recommend considering thromboprophylaxis with mechanical methods including IPC and GCS in combination with LMWH (class B recommendation). Thromboprophylaxis with IPC and GCS should be initiated on admission, and with LMWH when the bleeding risk is reduced to an acceptable level (class $\mathrm{C}$ recommendation). LMWH and IPC should be used for 3 months, and GCS should be used lifelong (class $\mathrm{C}$ recommendation).

\section{Burns}

Venous thromboembolism risk in patients with burns varies from low to high. All age groups are represented in this patient population. Other organ damage or concomitant conditions that require multidisciplinary approach and intensive care are present in some of these patients. Without thromboprophylaxis, the incidence of DVT detected by routine compression ultrasonography is $6-27 \%$. The rate of symptomatic VTE is $2.4-7 \%$.

Due to lack of evidence from research studies, thromboprophylaxis must be individualized, similarly 
to that in patients with multiple trauma. Recommendations for patients with burns are thus extrapolated from patients with multiple trauma.

\section{Recommendations}

In patients at an increased VTE risk, we recommend considering $\mathrm{LMWH}$ use (class $\mathrm{C}$ recommendation). Thromboprophylaxis should be initiated whenever it is considered safe, and should be continued for the period of an increased risk (class $\mathrm{C}$ recommendation).

\section{Medical patients: neurology}

\section{Acute hemorrhagic stroke}

Prevention of thromboembolic complications is a very important aspect of care in each patient with stroke, including patients with intracerebral hemorrhage. The effectiveness of GCS in patients with hemorrhagic stroke has not been clearly validated. UFH and LMWH decrease the incidence of thromboembolic events but increase the rate of bleeding complications. Use of UFH and LMWH in this patient group may be increased with an increased severity of intracerebral hemorrhage.

\section{Recommendations}

The authors of PCS 2017 recommend thromboprophylaxis using mechanical methods including GCS and IPC since the onset of hemorrhagic stroke (class $B$ recommendation).

Subcutaneous administration of LWMH or UFH in low doses may increase intracerebral bleeding. However, administration of low doses of LWMH or UFH is acceptable after 2-4 days since the onset of hemorrhagic stroke in patients at high risk of thromboembolic complications if the cause of hemorrhagic stroke, clinical presentation and/or imaging studies do not indicate progression of bleeding (class $\mathrm{C}$ recommendation).

\section{Acute ischemic stroke}

The incidence of VTE in patients with ischemic stroke is decreased by early patient ambulation, use of GCS and IPC, and pharmacological thromboprophylaxis with LWMH or UFH in low doses. Use of low doses of UFH and LWMH has been tested in several studies. Mechanical and pharmacological thromboprophylaxis should be continued during hospitalization and until the patient is mobilized.

\section{Recommendations}

The authors of PCS 2017 recommend as early physical rehabilitation as possible, aiming for early complete patient ambulation (class $\mathrm{C}$ recommendation).

The authors of PCS 2017 recommend subcutaneous $\mathrm{LMWH}$ administration as recommended by the drug manufacturer (class B recommendation) or UFH 5000 IU twice daily subcutaneously (class B recommendation).

It is recommended to use GCS and IPC as an addition to pharmacological thromboprophylaxis or as the method of choice in patients in whom anticoagulants are contraindicated (class $B$ recommendation).

\section{Acute medical conditions}

Acute medical conditions including congestive heart failure, respiratory disease (acute respiratory failure, exacerbation of chronic respiratory failure), infections, inflammatory disease, myocardial infarction, rheumatological disease, and malignancies are associated with a high risk of VTE. In addition to the risk directly related to the cause of hospitalization, overall individual thromboembolic risk is affected by individual patient characteristics such as elderly age, obesity, limited mobility, previous VTE event, acquired or hereditary thrombophilia, and use of hormonal therapy (oral contraception or HRT). For the assessment of individual VTE risk, the authors of PCS 2017 recommend using the Padua prediction score provided at the end of the present statement.

In extensive randomized studies conducted in patients hospitalized in medical wards, the incidence of DVT in control groups was 10-15\%.

Asymptomatic proximal DVT is associated with higher mortality compared to isolated calf DVT.

Autopsy studies indicate that about $75 \%$ of deaths due to PE in hospitalized patients occur in those treated for medical conditions.

Overall mortality among patients hospitalized due to an acute medical condition is about $10 \%$, and about $1 \%$ of hospital deaths are due to PE.

It has been estimated that without adequate thromboprophylaxis, fatal PE may occur in one in 20 hospitalized medical patients and it is the major cause of in-hospital sudden deaths.

Risk factors for VTE in patients hospitalized in medical wards include active malignancy, previous VTE event, limited mobility, confirmed thrombophilia, recent (within one months) trauma and/or surgery, recent acute myocardial infarction, ischemic stroke, acute infection, presence of a rheumatological disease, obesity [body mass index $\left.(\mathrm{BMI}) \geq 30 \mathrm{~kg} / \mathrm{m}^{2}\right)$ ], and use of hormonal therapy.

Factors that increase the risk of bleeding complications include active gastric or duodenal peptic ulcer, bleeding within 3 months before hospitalization, platelet count $<50,000 / \mu \mathrm{L}$, age $\geq 85$ years, hepatic failure (INR $>$ I.5), renal failure [glomerular filtration rate (GFR) $<30 \mathrm{~mL} / \mathrm{min} / \mathrm{m}^{2}$ ], active malignancy, poorly controlled hypertension, admission to an intensive care unit, and rheumatological disease. 
In the recently published Acute Medically III Venous Thromboembolism Prevention with Extended Duration Betrixaban (APEX) study, an oral direct active factor $X$ inhibitor betrixaban was found to be effective in extended (for up to 6 weeks) thromboprophylaxis in medical patients without a significant increase in the rate of bleeding complications. This drug will be probably soon licensed for extended thromboprophylaxis in hospitalized medical patients $[19,20]$. An increased VTE risk following hospital discharge was determined by age $>75$ years, increased (twice above the cut-off value) D-dimer level, and immobility that accompanied medical conditions listed above.

\section{Recommendations}

In patients hospitalized due to an acute medical condition, the authors of PCS 2017 recommend an individual assessment of the risk of thromboembolic and bleeding complications in each patient (class $\mathrm{C}$ recommendation).

Pharmacological thromboprophylaxis using LMWH, UFH in low doses administered subcutaneously two or three times a day, or fondaparinux is recommended by the authors of PCS 2017 in patients at an increased risk of thromboembolic complications (class A recommendation), with drug dosing as recommended in the SPC.

If bleeding risk is judged as high or symptoms/ /signs of bleeding are present in the patient, we suggest using mechanical methods including GCS and IPC (class $C$ recommendation). If the risk of bleeding complications is reduced but the risk of thromboembolic complications remains increased, the authors of PCS 2017 recommend substituting pharmacological thromboprophylaxis for mechanical methods (class B recommendation).

Routine extension of thromboprophylaxis beyond the hospital discharge is currently not recommended.

\section{Intensive care}

The incidence of DVT in patients hospitalized in intensive care units is high, ranging from 25 to $32 \%$. In addition to immobilization, several other risk factors VTE are present in most patients in whom thromboembolic complications develop.

Due to multiple comorbidities and their severe clinical status, patients managed in intensive care units are a population at an increased risk of both thromboembolic and bleeding complications. Conditions that increase bleeding risk, including thrombocytopenia, peptic ulcer disease, and multiorgan failure (including renal failure and hepatic failure) are more common in this patient group.

When deciding on the approach to thromboprophylaxis, all additional patient conditions that may limit or preclude using specific thromboprophylaxis methods should be taken into account (e.g., the presence of advance atherosclerotic lesions in lower limb arteries is a contraindication to mechanical methods, and they obviously cannot be used following limb amputation).

Thus, the decision regarding the choice of thromboprophylaxis method should be made individually in each patient, considering contraindications to and limitations of the available methods.

\section{Recommendations}

We recommend using LMWH or UFH in low doses, unless contraindications exist that limit use of these methods (class A recommendations). We recommend drug dosing as stated in the SPC.

LMWH are preferred as these drugs are administered once daily and the risk of HIT is lower compared to UFH.

An increase in nadroparin dose should be considered in patients with body weight $>70 \mathrm{~kg}$ who are ventilated due to respiratory failure secondary to exacerbated chronic obstructive pulmonary disease (COPD).

Use of mechanical methods, including GCS and/or IPC/FIT, is recommended in patients with contraindications to pharmacological thromboprophylaxis (class C recommendation).

If no contraindications exist, we suggesting combining mechanical and pharmacological thromboprophylaxis (class $\mathrm{C}$ recommendation).

We do not recommend routine screening lower limb venous ultrasonography (USG) to detect asymptomatic DVT (class $C$ recommendation).

\section{Diagnosis of deep venous thrombosis and pulmonary embolism}

\section{Diagnosis of deep venous thrombosis}

Clinical symptoms and signs of DVT include edema, reddening, limb pain, dilation of superficial veins, calf pain during foot dorsiflexion, tenderness along the course of the vein, and increased warmth of the affected limb [2I]. However, the specificity of these symptoms and signs is inadequate and thus the diagnosis cannot be made based on clinical symptoms and signs only. Of note, DVT is ultimately confirmed in only $20 \%$ patients with clinical symptoms and signs suggesting DVT.

The diagnosis of DVT is based on:

- assessment of the clinical probability - for this purpose, the Wells prediction score is recommended [2I]

(provided at the end of the present document);

- measurement of D-dimer level;

- performing a diagnostic test. 
Based on the estimated clinical DVT likelihood, the patients are categorized as being at high, moderate, or low probability of DVT. However, the evaluation of the clinical probability is not synonymous with the clinical diagnosis. In patients with low and moderate clinical probability of DVT, D-dimer level should be measured, and if it is below the cut-off value, the diagnosis of DVT may be excluded with a high probability. With this approach, diagnostic imaging studies do not need to be performed in about $30 \%$ of patients. DVT may be safely excluded using the above strategy, as this diagnosis is confirmed in only $1 \%$ of patients within 3 months after the procedure.

In patients in whom the suspicion of DVT has been considered "very likely", deep vein ultrasonography as a diagnostic test should be performed as soon as possible. D-dimer level should not be measured as a part of the decision process in these patients.

Ultrasonography of the whole deep venous system, both proximal and distal, should be performed. This ultrasonographic modality increases the number of appropriately diagnosed symptomatic DVT cases by I5\%.

Ultrasonography of the deep venous system limited to several points has a lower sensitivity for the diagnosis of DVT.

In cancer patients and hospitalized patients with suspected DVT, ultrasonography should be performed as soon as possible (D-dimer level should not be measured as a part of the decision process) as the likelihood of DVT in these patient groups is high.

In patients aged $>50$ years, the cut-off $D$-dimer level has been increased according to the following formula: age $\times 10 \mu \mathrm{g} / \mathrm{L}$ (standard cut-off level is 500 $\mu \mathrm{g} / \mathrm{L})$. The sensitivity and specificity of the new definition of cut-off D-dimer level is being evaluated in clinical studies.

In patients with a high clinical probability of DVT, and patients with a moderate or low probability of DVT but D-dimer level above the cut-off value, compression ultrasonography should be performed as a diagnostic test.

In patients with a high clinical probability of DVT and D-dimer level above the cut-off value, ultrasonography of the deep venous system should be repeated if the first study yielded a negative result [2I].

Computed tomography (CT) venography and magnetic resonance venography are currently of a lesser importance as diagnostic tools.

\section{Recommendations}

We recommend diagnosing DVT using the diagnostic approach based on the evaluation of the clinical probability of DVT, D-dimer level measurements, and compression ultrasonography of the deep venous system (class A recommendation).

\section{Diagnosis of pulmonary embolism}

The diagnosis of PE may be divided into three steps. The first step is the evaluation of the hemodynamic status of the patient [2I, 22]. This step involves identification of patients in shock or hypotension that cannot be explained by other causes. A finding of significant hemodynamic disturbances in a patient with suspected PE determines the subsequent management which includes:

- hospitalization in an intensive care unit;

- monitoring of vital parameters;

- immediate intravenous heparin administration;

- urgent imaging studies of the pulmonary circulation; and

- systemic thrombolysis after the suspicion of PE is confirmed.

The second step of the diagnostic approach is the clinical evaluation in patients without the above mentioned hemodynamic disturbances. This includes:

- evaluation of clinical symptoms and signs;

- performing basic laboratory tests (chest roentgenogram, ECG, arterial blood gases, D-dimer level);

- evaluation of VTE risk factors; and

- determination of the clinical probability of PE using established clinical prediction rules (recommended tools include the Wells score and the Geneva score which are provided at the end of the present document).

In each patient with $\mathrm{PE}$, prognosis should be evaluated using the Pulmonary Embolism Severity Index (PESI) which is provided at the end of the present document; the simplified PESI (sPESI) may be used.

Clinical symptoms and signs of PE are not specific. History and physical examination do not usually allow the diagnosis of PE to be made but are sufficient to suspect PE. The most common symptoms of PE are dyspnea, chest pain, and tachypnea, seen in more than $50 \%$ of patients. Less frequent symptoms include cough, syncope, and hemoptysis (usually in 20-30\% of patients). The most common signs include tachycardia, localized rales, and fever. Symptoms and signs of venous thrombosis are seen in only about one third of patients with PE.

Syncope is a prognostically ominous symptom that usually reflects a reduced circulatory reserve. Chest pain may be twofold in nature. In some cases, it is typical pleuritic pain, increasing during cough or deep breathing, which results from pleural irritation in peripheral PE; it is usually accompanied by lung infarctions and pleural effusion. Another type of chest pain in PE is retrosternal pain resulting from right ventricular hypoxia; it may be associated with central PE associated with worse prognosis. Hemoptysis usually occurs in patients with lung infarctions and is not a contraindication to 
anticoagulation. If hemoptysis persists or is severe, bronchoscopy is indicated.

In some cases, PE is asymptomatic and may be detected incidentally during diagnostic testing performed for other reasons.

Basic diagnostic tests in patients with PE usually show some abnormalities.

Chest roentgenogram may show lung consolidations, pleural effusion, elevated hemidiaphragm, or dilated intermediate pulmonary artery

Electrocardiography (ECG) may show arrhythmia (mostly supraventricular, including atrial fibrillation), changes of the electrical axis of the heart and conduction within the right bundle branch (right axis deviation, SIQIII configuration, incomplete right bundle branch block), and negative $\mathrm{T}$ waves in leads V2-V3, V4-6 (pseudo-infarction pattern).

Arterial blood gases usually show hypoxemia, hypocapnia, and respiratory alkalosis.

An issue of major importance is to include PE in the differential diagnosis in everyday clinical practice. None of the mentioned diagnostic tests is sensitive or specific for PE. However, they are important diagnostic tools in the general evaluation of the patient and allow exclusion of other alternative diagnoses.

An important component of the clinical evaluation is D-dimer level measurement. D-dimer is a product of plasmin-mediated degradation of stabilized fibrin. Its level increases in all processes associated with thrombus formation. D-dimer level below the cut-off value may help exclude PE, if evaluated using an adequately sensitive test. It should be remembered, however, that an elevated D-dimer level neither confirms nor excludes PE. In clinical practice, D-dimer level is measured only in patients with a non-high clinical probability of PE, using tests that have been evaluated in long-term studies. Normal D-dimer level has a negative predictive value and allows safe exclusion of PE in $30-40 \%$ of patients with a non-high clinical probability of PE. The utility of D-dimer level measurements needs to be carefully considered in hospitalized patients, the elderly, patients with malignancy, and pregnant women.

The third step of the diagnostic approach involves imaging of the pulmonary circulation which is performed:

- on an urgent basis in hemodynamically unstable patients; and

- in hemodynamically stable patients in whom PE could not be excluded based on the clinical evaluation.

Currently, the major diagnostic study to image the pulmonary circulation is CT pulmonary angiography, usually performed using multidetector CT scanners. This is related to wide availability of CT scanners, rap- id image acquisition, and excellent resolution of CT images. CT pulmonary angiography nearly completely replaced conventional pulmonary arteriography which was considered the gold diagnostic standard until recently. Pulmonary arteriography is an invasive method which is not widely available, is associated with a risk of bleeding complications, and does not allow alternative diagnoses to be made. Ventilation-perfusion lung scintigraphy is rarely used for the diagnosis of PE. Ventilation scintigraphy is essentially not performed, and the value of scintigraphy is limited, as most studies are non-diagnostic (up to $90 \%$ of studies in COPD patients). In addition, up to $25-30 \%$ of low- and moderate probability scans are prone to discordant interpretation.

\section{Recommendations}

Pulmonary embolism may only be suspected based on clinical evaluation, ECG, chest roentgenogram, and arterial blood gases. Suspicion of PE should prompt heparin administration (if not contraindicated) followed by diagnostic tests to confirm or exclude this condition definitely (class $\mathrm{C}$ recommendation).

The hemodynamic status of the patient determines the urgency of imaging studies. In hemodynamically stable patient, the clinical probability of PE should be evaluated using validated clinical prediction scores (class $A$ recommendation).

Pulmonary embolism may be confirmed by CT pulmonary angiography, high-probability lung scan, or invasive pulmonary arteriography. The current diagnostic gold standard is CT pulmonary angiography (class A recommendation).

D-dimer level measurement and perfusion lung scintigraphy are mostly used to exclude PE in the outpatient population and in patient with a low clinical probability of $\mathrm{PE}$ (class $\mathrm{A}$ recommendation).

The utility of perfusion lung scintigraphy is limited to cases with normal chest roentgenogram in patients without concomitant lung disease (class $\mathrm{C}$ recommendation).

\section{Treatment of deep vein thrombosis and pulmonary embolism}

The goals of acute DVT management include prevention of mortality and disability, as well as pulmonary hypertension and peripheral venous disease. Further goals are to prevent VTE and the development of chronic venous disease due to persistent venous obstruction and/or valve dysfunction. Acute extension of DVT and progressive lower limb edema may result in intracompartmental pressure rise, sometimes leading to phlegmasia cerulea dolens, venous gangrene, and limb loss. 
The initial management in patients with DVT and PE may involve administration of UFH, LMWH, fondaparinux, rivaroxaban, or apixaban. If chronic treatment with VKA, dabigatran, or edoxaban is planned, initial parenteral heparin therapy is required [2I-24].

\section{Anticoagulation in the acute phase of DVT and PE}

Intravenous UFH administration as a continuous infusion (initially not less than I $250 \mathrm{IU}$ per hour) must be preceded by administration of an UFH bolus (not less than $5000 \mathrm{IU}$ ). Such therapy requires hospital admission and is currently rarely used. However, if UFH is used for the initial treatment of DVT, rapid achievement (within 24 hours) and maintaining the activated partial thromboplastin time (APTT) in the therapeutic range (I.5-2.5 times the control value) is associated with a reduced venous thrombosis recurrence rate [2I, 22].

Results of the randomized trials and clinical practice led to substitution of subcutaneous LWMH for UFH in the treatment of DVT. LWMH are also effective in patients with PE. Thus, anticoagulation should be usually initiated with LMWH - the exception are hemodynamically unstable patients [21, 22].

Low-molecular weight heparins are characterized by a constant dose-effect relationship and predictable bioavailability following subcutaneous administration. These drugs do not require laboratory monitoring (except for platelet count). The need for monitoring anti-Xa activity is limited to individual dosing of specific drugs in renal failure and morbid obesity (detailed information on specific drugs is available in drug reference sources). These drugs may be administered once daily. For these reasons, LMWH are the preferred drugs in patients with uncomplicated DVT treated on an outpatient basis.

Treatment with fondaparinux is an alternative approach to the management of DVT and PE in the acute phase. This drug is administered once daily.

Initial anticoagulant therapy with heparin is necessary if long-term treatment with dabigatran or edoxaban is planned [21, 22, 25]. Apixaban (initial dose $10 \mathrm{mg}$ twice daily recommended for the first 7 days) and rivaroxaban (initial higher dose $15 \mathrm{mg}$ twice daily is used for the first 21 days) may be used as monotherapy in the acute phase of DVT and PE $[23,24]$.

If long-term VKA therapy is planned, the drug dose should be adjusted to maintain INR in the range of 2.0-3.0 (in the acute phase concomitantly with heparin treatment): the target INR value is 2.5 [2I, 22].

INR values $>4$ are associated with an increased rate of bleeding complications. Administration of VKA should be initiated on the first day of heparin therapy, except for patients who require thrombolysis or surgery, with concomitant malignancy, and in case of concomitant conditions that predispose to major bleeding.

Unfractionated heparin or LMWH should be administered for at least 5 days and withdrawn when stable INR values in the therapeutic range (2-3) are achieved.

We believe that in the Polish settings, all patients with an acute PE event (even with low mortality risk as evaluated using PESI or SPESI) should be hospitalized during the acute treatment phase, as no system of outpatient care for such patients exists in our country.

\section{Recommendations}

In patients with DVT and PE, initial treatment involves using $\mathrm{UFH}, \mathrm{LMWH}$, fondaparinux (class $\mathrm{A}$ recommendation), rivaroxaban, or apixaban (class $B$ recommendation).

If chronic VKA treatment is planned, initial parenteral heparin therapy is required (class $A$ recommendation). Edoxaban and dabigatran may be used following LMWH treatment for 5 days.

Anticoagulant therapy should usually be initiated with $L M W H$ (class A recommendation).

If chronic VKA treatment is planned, the drug dose should be adjusted to maintain INR in the range of 2-3 (in the acute phase concomitantly with heparin treatment): the target INR value is 2.5 (class A recommendation).

We believe that in the Polish settings, all patients with an acute PE event (even with low mortality risk) should be hospitalized during the initial treatment phase (class $\mathrm{Cl}$ recommendation).

\section{Long-term anticoagulant therapy following an acute DVT or PE event and extended secondary VTE prevention}

The first three months of anticoagulant therapy are called long-term anticoagulant therapy. The period beyond the first 3 months, if anticoagulant drugs are continued, is known as extended secondary VTE prevention (therapy with no scheduled stop date) [I].

In all patients with proximal DVT and patients with $\mathrm{PE}$, anticoagulant therapy for a period not shorter than 3 months is recommended [ $1,21,22]$.

During the first 3 months, it is recommended to use oral direct factor Xa inhibitors (apixaban, edoxaban or rivaroxaban) or oral direct factor lla inhibitors (dabigatran) [I]. VKA therapy during the first 3 months is similarly effective as treatment with oral factor $\mathrm{Xa}$ and lla inhibitors but it was found to be associated with an increased rate of bleeding complications, as confirmed in clinical trials. Thus, VKA therapy should be considered a second-choice treatment [I]. Long-term LMWH use is recommended if DVT or PE developed secondary to a malignancy [ $I]$.

In patients with VTE and concomitant coronary artery disease, oral factor $\mathrm{Xa}$ inhibitors or VKA are 
preferred, as acute coronary syndromes (ACS) were observed more frequently during long-term anticoagulant therapy with dabigatran compared to VKA [I]. This issue has not been fully clarified and remains controversial. An increased incidence of ACS was not seen during treatment with factor $X a$ inhibitors.

In patients with VTE and malignancy, oral direct factor $X a$ and factor lla inhibitors and VKA may be used if therapy with LMWH is contraindicated [I].

If extended secondary VTE prevention is used (beyond the first 3 months of therapy), the previously chosen drug may be continued. A change of drug is indicated in case of adverse effects or if the treatment safety needs to be increased (by reducing the likelihood of bleeding complications) while preserving an adequate level of treatment effectiveness. For extended secondary VTE prevention, options include oral direct factor Xa inhibitors [apixaban (2.5 mg twice daily), edoxaban, rivaroxaban (see Appendix for information regarding the reduced $10 \mathrm{mg}$ dose)], factor lla inhibitors (dabigatran), VKA [I], and sulodexide in patients after DVT [500 lipasemic units (LSU) twice daily] [26].

The rate of recurrent VTE during use of oral factor $\mathrm{Xa}$ and factor Ila inhibitors for extended secondary VTE prevention is reduced by more than $80 \%$ compared to placebo. Sulodexide reduces VTE recurrences by $55 \%$, and acetylsalicylic acid by about $30 \%$ [1, 24-30].

Of note, chronic use of sulodexide is not associated with an increase in the rate of major or clinically relevant bleedings as defined by the International Society on Thrombosis and Haemostasis (ISTH) [3I]. This drug is thus acceptably effective and very safe [26]. Both these factors are important when evaluating the quality of anticoagulant therapy [26].

It should be stressed that acetylsalicylic acid is not an alternative for anticoagulants used for extended secondary VTE prevention. However, if anticoagulant therapy is stopped (for various reasons, including patient decision), use of acetylsalicylic acid is beneficial as it is associated with a reduced likelihood of VTE recurrence $[29,30]$.

Use of sulodexide for extended secondary VTE prevention is associated with a relative risk reduction by about $55 \%$ (except in patients with severe thrombophilia) and very low rates of both major bleeding and clinically relevant less major bleeding. The highest net clinical benefit related to anticoagulant use for extended secondary VTE prevention, taking into account VTE recurrences and clinically relevant bleeding complications, was found for apixaban and sulodexide.

In patients with a first episode of proximal DVT or acute $\mathrm{PE}$ provoked by a surgical procedure, anticoagulation for 3 months is recommended [I]. Neither shorter nor longer treatment duration is not recommended [I].
In patients with a VTE event provoked by a surgical procedure, the 5-year risk of DVT or PE recurrence is $3 \%[\mathrm{I}]$.

In all patients with proximal DVT and PE provoked by transient risk factors (other than a surgical procedure, e.g., estrogen therapy, pregnancy, plaster cast, a flight lasting $>8$ hours), anticoagulation for 3 months is recommended [ $\mathrm{I}]$. Neither shorter nor longer treatment duration is not recommended [ $\mathrm{I}]$ even if the risk of bleeding complication is moderate or low.

In patients with transient risk factors (listed above) not related to a surgical procedure, the 5-year risk of VTE recurrence is about $15 \%[\mathrm{I}]$.

Isolated symptomatic distal DVT, both idiopathic and provoked by a surgical procedure or other transient risk factors, requires anticoagulation for 3 months. Neither shorter nor longer treatment duration is not recommended [I].

Note: In all patients with idiopathic VTE, the risk of DVT or PE recurrence and the risk of bleeding complications should be reevaluated after the first 3 months of treatment.

The risk of VTE recurrence is evaluated by taking into account the following factors:

- gender (recurrence risk is I.75 times higher in men compared to women);

- patient age (recurrence risk is higher in younger patients);

- presence of residual thrombi;

- D-dimer level in patients who discontinued anticoagulation (increased D-dimer level at one month after discontinuation of anticoagulation is associated with a 2 -fold increase in the recurrence risk) [1, 32-35].

The safety and risk profile should be reevaluated every 3-6 months.

An unprovoked first episode of proximal DVT or PE (idiopathic VTE) is associated with a high risk of recurrence following discontinuation of anticoagulation (6-10\% at I year, $20 \%$ at 2 years and $30 \%$ at 5 years) [I]. In patients with distal DVT, the recurrence risk is $50 \%$ lower, and in patients with a second episode of idiopathic DVT or unprovoked PE it is $50 \%$ higher compared to the risk associated with the first VTE episode [1, 32-35].

The decision regarding discontinuation of anticoagulation should be based on an analysis of the risk of major bleeding complications. According to the 2016 ACCP guidelines, risk factors for major bleeding include age $>65$ years, age $>75$ years, a history of a bleeding complication, malignancy, the presence of metastases, renal failure, hepatic failure, thrombocytopenia, a history of stroke, diabetes, anemia, antiplatelet therapy, poorly controlled anticoagulation, major comorbidities 
associated with functional impairment, recent surgery, a history of frequent trauma, alcohol abuse, use of non-steroidal anti-inflammatory drugs (NSAID), and major mobility limitation [I]. The authors of PCS 2017 added poorly controlled hypertension to this list.

The risk of bleeding complications may be divided into three categories:

- low risk - risk factors listed above are absent; the annual major bleeding risk is $0.8 \%$;

- moderate risk - one risk factor listed above is present; the annual major bleeding risk is $1.6 \%$;

- high risk — $\geq 2$ risk factors listed above are present; the annual major bleeding risk is $\geq 6.5 \%$.

First idiopathic (unprovoked) proximal DVT or PE requires obligatory anticoagulation for 3 months. In patients with low or moderate risk of bleeding complications, extended secondary VTE prevention using factor Xa inhibitors (apixaban, edoxaban, rivaroxaban), factor Ila inhibitors (dabigatran), VKA [I], or sulodexide (only DVT cases) is indicated [28].

In patients with a first episode of idiopathic proximal DVT and a high risk of bleeding complications, the authors of the 2016 ACCP guidelines did not recommend extension of anticoagulant therapy [I].

Based on the results of the Secondary Prevention of Recurrent Deep Vein Thrombosis (SURVET) study [26], however, the authors of PCS 2017 recommend use of sulodexide for extended secondary VTE prevention in this patient group, taking into account a highly favorable safety profile and an acceptable efficacy of this drug [26].

In patients with a first episode of idiopathic PE and a high risk of bleeding complications, the authors of the most recent ACCP guidelines did not recommend extension of anticoagulant therapy [I].

However, the authors of PCS 2017 recommend extended secondary VTE prevention using oral factor $\mathrm{Xa}$ or factor lla inhibitors (safer than VKA) in reduced doses adjusted to the risk of bleeding (information regarding rivaroxaban $10 \mathrm{mg}$ dose is provided in the Appendix).

Scientific data on sulodexide in patients with PE are not sufficient to recommend this drug for this indication.

In patients with idiopathic VTE (DVT and PE) in whom anticoagulation has been discontinued, acetylsalicylic acid $100 \mathrm{mg}$ per day is indicated (if no contraindications to this therapy exist) $[1,29,30]$. It should be noted that the effectiveness of acetylsalicylic acid for extended secondary VTE prevention is much lower compared to that of factor Xa inhibitors, factor Ila inhibitors, and sulodexide.

DVT and PE recurrences in patients with idiopathic VTE (following initial treatment and long-term anticoagulant therapy) require extended secondary VTE prevention if the bleeding risk is low or moderate. In these settings, all the above listed drugs can be used $[1,26]$.

In patients with a high bleeding risk and recurrent DVT (following initial treatment and long-term anticoagulant therapy), we recommend extended secondary VTE prevention using sulodexide [26].

\section{Recommendations for patients with VTE and no concomitant malignancy}

In all patients with proximal DVT and PE, we recommend anticoagulation for not less than 3 months (class A recommendation).

For the first 3 months of treatment, the preferred drugs are oral direct factor $\mathrm{Xa}$ inhibitors (apixaban, edoxaban, or rivaroxaban) or oral direct factor lla inhibitors (dabigatran) (class $B$ recommendation) and VKA (similar treatment efficacy but lower safety compared to oral factor Xa and factor Ila inhibitors).

For extended secondary VTE prevention, we recommend oral direct factor Xa inhibitors [apixaban (2.5 $\mathrm{mg}$ twice daily), edoxaban, rivaroxaban (information regarding the efficacy and safety of rivaroxaban $10 \mathrm{mg}$ dose is provided in the Appendix)], factor lla inhibitors (dabigatran), VKA, and sulodexide (500 LSU twice daily), the latter offering somewhat lower efficacy compared to oral factor Xa and factor Ila inhibitors but very high safety of extended secondary VTE prevention (class $\mathrm{B}$ recommendation).

In patients with a first episode of proximal DVT or acute PE provoked by a surgical procedure, anticoagulation for 3 months is recommended. Neither shorter nor longer treatment duration is not recommended (class A recommendation).

In all patients with proximal DVT and PE provoked by transient risk factors (other than a surgical procedure), anticoagulation for 3 months is recommended. Neither shorter nor longer treatment duration is not recommended (class $B$ recommendation).

Isolated symptomatic distal DVT, both idiopathic and provoked by a surgical procedure or other transient risk factors, requires anticoagulation for 3 months. Neither shorter nor longer treatment duration is not recommended (class B recommendation).

First idiopathic (unprovoked) proximal DVT or $P E$ requires obligatory anticoagulation for 3 months. In patients with low or moderate risk of bleeding complications, extended secondary VTE prevention using factor $\mathrm{Xa}$ inhibitors (apixaban, edoxaban, rivaroxaban), factor lla inhibitors (dabigatran), VKA, or sulodexide (only DVT cases - although the efficacy of sulodexide is somewhat lower, very high treatment safety should also be considered) is indicated (class B recommendation). 
In patients with a first episode of idiopathic proximal DVT and a high risk of bleeding complications, the authors of PCS 2017 recommend sulodexide for extended secondary VTE prevention due to a highly favorable safety profile and acceptable efficacy of this drug (class $B$ recommendation).

In patients with a first episode of idiopathic PE and a high risk of bleeding complications, the authors of PCS 2017 recommend extended secondary VTE prevention using oral factor $\mathrm{Xa}$ or factor Ila inhibitors in reduced doses adjusted to the risk of bleeding (information regarding rivaroxaban $10 \mathrm{mg}$ dose is provided in the Appendix). When choosing the drug, the availability of a specific antidote should also be considered (class $\mathrm{Cl}$ recommendation).

In patients with idiopathic VTE (DVT and PE) in whom anticoagulation has been discontinued, consideration of acetylsalicylic acid $100 \mathrm{mg}$ per day is indicated (if no contraindications to this therapy exist) (class $B$ recommendation).

DVT and $P E$ recurrences in patients with idiopathic VTE (following initial treatment and long-term anticoagulant therapy) require extended secondary VTE prevention if the bleeding risk is low or moderate. In these settings, all the above listed drugs can be used (class $\mathrm{A}$ recommendation).

In patients with a high bleeding risk and recurrent DVT (following initial treatment and long-term anticoagulant therapy), we recommend extended secondary VTE prevention using sulodexide (class B recommendation).

In patients with a high bleeding risk and recurrent $\mathrm{PE}$ (following initial treatment and long-term anticoagulant therapy), we recommend extended secondary VTE prevention using oral factor $\mathrm{Xa}$ and factor Ila inhibitors in reduced doses. When choosing the drug, the availability of a specific antidote should be considered (class Cl recommendation).

\section{Isolated distal deep vein thrombosis}

The management of incidentally detected isolated distal DVT remains controversial. It should be noted that only 15\% cases of untreated isolated distal DVT propagate to the popliteal vein and may cause PE. Risk factors for propagation of isolated distal thrombosis to the popliteal vein, favoring anticoagulation, include:

- D-dimer level above the cut-off value;

- thrombosis involving veins $>5 \mathrm{~cm}$ in length, $>7$ $\mathrm{mm}$ in diameter;

- thrombosis close to the popliteal vein;

- idiopathic thrombosis;

- concomitant malignancy;

- previous DVT event;

- occurrence of DVT during hospitalization.
It is believed that thrombosis in intramuscular veins is less likely to propagate compared to that involving the tibial and peroneal veins.

If distal DVT is asymptomatic and risk factors for thrombosis propagation are not present, many experts suggest serial deep vein ultrasonography (within 2 weeks) over anticoagulation, particularly in patients at high risk of bleeding complications [I].

In the Polish settings, serial ultrasonography is associated with high costs and logistic problems. The authors of PCS 2017 recommend initiation of anticoagulation if serial deep vein ultrasonography is not feasible and the risk of bleeding is moderate or low.

If the risk of bleeding is high, serial ultrasonography is recommended [ $\mathrm{I}]$.

In patients with isolated asymptomatic distal DVT in whom serial deep vein ultrasonography is chosen, initiation of anticoagulation is required if thrombosis propagation within the distal and/or proximal venous system is identified [I].

In patients in whom a suspicion of symptomatic distal DVT was confirmed by ultrasonography, anticoagulation for 3 months should be initiated [I] as recommended in PCS 2017.

\section{Recommendations}

If distal DVT is asymptomatic and risk factors for thrombosis propagation are not present, serial deep vein ultrasonography within 2 weeks is recommended over anticoagulation, particularly in patients at high risk of bleeding complications (class $\mathrm{C}$ recommendation).

Initiation of anticoagulation in asymptomatic distal DVT is recommended if serial deep vein ultrasonography is not feasible and the risk of bleeding is moderate or low (class $\mathrm{Cl}$ recommendation).

In patients with isolated asymptomatic distal DVT in whom serial deep vein ultrasonography is chosen, initiation of anticoagulation is required if thrombosis propagation within the distal and/or proximal venous system is identified (class $B$ recommendation).

In patients in whom a suspicion of symptomatic distal DVT was confirmed by ultrasonography, anticoagulation for 3 months should be initiated (class $A$ recommendation).

\section{Anticoagulation in patients with isolated subsegmental pulmonary embolism}

Anticoagulation in patients with PE limited to subsegmental vessels is controversial. Subsegmental PE is detected in about $10 \%$ of patients with suspected PE referred for CT pulmonary angiography. Some of these cases may be false positive PE diagnoses, but some thrombi may originate from the distal segment, where DVT is less likely to progress [I]. 
In patients in whom CT pulmonary angiography shows isolated subsegmental thrombi but no thrombi have been identified in the lower limb deep venous system (in the proximal segment) and no upper limb DVT was found (in patients with implanted catheters), anticoagulation is not recommended. Serial ultrasonography of the deep venous system is recommended in such cases [I].

It should be noted, however, that the diagnostic methods currently used to detect DVT are inadequately sensitive (about $60-80 \%$ ), particularly in patients with asymptomatic venous thrombosis. Thus, serial ultrasonography as a diagnostic tool to detect proximal DVT in asymptomatic patients has been considered a suboptimally effective screening method by the authors of the present consensus statement [36].

Detection of an isolated thrombus in a subsegmental pulmonary artery favors anticoagulation for 3 months if:

- the patient is hospitalized for some other condition;

- the patient is immobilized;

- a concomitant malignancy is present;

- low cardiopulmonary reserve has been found;

- clinical symptoms of PE are present that cannot be attributed to other conditions [I, 37].

\section{Recommendations}

In patients in whom CT pulmonary angiography shows isolated subsegmental thrombi but no thrombi have been identified in the lower limb deep venous system (in the proximal segment) and no upper limb DVT was found (in patients with implanted catheters), anticoagulation is not recommended (class $C$ recommendation). However, decisions have to be made individually, taking into account the presence of VTE risk factors and the bleeding risk. Serial ultrasonography of the deep venous system is recommended in such cases (class $\mathrm{C}$ recommendation).

\section{Management of venous thromboembolism in patients with malignancy}

The Polish recommendations on the prevention and management of VTE in patients with malignancy were published in 2016 [38] in the "Onkologia w praktyce klinicznej" journal (2016; 12: 67-91). The authors of PCS 2016 fully agree with this statement and endorse these recommendations.

The chapter on this issue included in PCS 2017 only supplements these 2016 recommendations.

Malignancy-associated VTE occurs in a patient with an active malignancy or is a result of oncological therapy. Management of VTE in patients with malignancy is one of the most difficult clinical challenges as it often coincides with cancer treatment. Oncological therapy often requires invasive surgical procedures, is associat- ed with an increased risk of infections, and may result in thrombocytopenia, thus increasing the bleeding risk. In addition, a higher rate of recurrent thrombosis and a high risk of bleeding complications in this patient group must be considered when managing VTE in patients with malignancy.

In patients with an active malignancy and concomitant VTE, the 2016 ACCP guidelines recommend extended secondary VTE prevention beyond 3 months regardless of the bleeding risk. LMWH are the primary anticoagulant drugs for acute treatment, long-term anticoagulant therapy, and extended secondary VTE prevention [39-42].

In many patients with malignancy, it is difficult to predict the period of a significantly increased VTE risk. In all patients who require chronic anticoagulation, period reevaluation of the bleeding risk and the risk of recurrent $\mathrm{VTE}$ is required to balance treatment benefits with the risk of treatment complications.

An analysis of the Cochrane database [43] that included 7 prospective randomized clinical trials comparing LMWH with long-term oral VKA therapy showed a statistically significant, nearly $50 \%$ reduction of the risk of recurrent VTE in the LMWH group [hazard ratio (HR) $0.47 ; 95 \%$ confidence interval (CI) $0.32-0.7 \mathrm{I}$ ] with a comparable risk of major and clinically significant bleeding complication in both patient groups.

For the management of malignancy-associated VTE, it is suggested to increase the duration of the initial treatment with full therapeutic LMWH dose to at least one month, followed by drug dose reduction to $70-80 \%$ of the baseline therapeutic dose or continuation of full therapeutic dose until at least 3 months of treatment. The optimal duration of LMWH treatment for malignancy-associated VTE is still unknown. Recently, the Dalteparin Sodium for the Long-Term Management of Venous Thromboembolism in Cancer Patients (DALTECAN) study has been published that evaluated the safety of dalteparin for VTE treatment in patients with malignancy in the period between 6 and $I 2$ months of therapy. Among 334 patients included in the study, DVT was diagnosed in $49.1 \%$ of patients, PE in $38.9 \%$ of patients, and both conditions were identified in $12.0 \%$ of patients. The overall rate of major bleeding was $10.2 \%$, including $3.6 \%$ at one month, and $1.1 \%$ and $0.7 \%$ per month, respectively, between 2 and 6 months and between 7 and 12 months of therapy. Recurrent VTE was noted in $11.1 \%$ (37/334) of patients, including $5.7 \%$ at one month, $3.4 \%$ between 2 and 6 months of therapy, and $4.1 \%$ between 7 and 12 months of therapy. During the study, 116 patients died, including 4 due to recurrent VTE and 2 due to bleeding. The rate of major bleeding was lower beyond 6 months of dalteparin 
therapy. The risk of major bleeding complications and VTE recurrence was the highest during the first month of therapy and decreased over the next II months of therapy [44].

In case of recurrent VTE in an anticoagulated patient with malignancy, the type and quality of the previous anticoagulant therapy and other potential risk factors for recurrence should be assessed. If a recurrent VTE event is diagnosed, it is suggested to consider one of the proposed management approaches following an individual assessment of the risks and benefits of treatment:

- switch to LWMH at a full therapeutic dose in patients on VKA;

- increase LMWH dose by $20-30 \%$ in patients receiving long-term LMWH therapy;

- consider implantation of an inferior vena cava filter in case of VTE recurrence manifesting as PE during adequate (and continued) anticoagulation [I].

\section{Recommendations}

For acute treatment of DVT in patients with malignancy, LMWH are recommended as the preferred anticoagulants (class $\mathrm{A}$ recommendation).

Unfractionated heparin and fondaparinux may be considered alternative anticoagulants for acute treatment in patients with malignancy (class A recommendation).

Oral direct factor $\mathrm{Xa}$ inhibitors are currently not recommended for acute treatment of malignancy-associated thrombosis (class $\mathrm{C}$ recommendation).

In case of incidentally found DVT in a patient with malignancy, the same treatment is recommended as in symptomatic VTE (class C recommendation).

For long-term therapy and extended secondary VTE prevention in patients with malignancy, LMWH use for at least 3-6 months is recommended (class A recommendation).

For long-term therapy, a therapeutic LMWH dose is recommended for at least one month since therapy initiation, followed by a therapeutic or reduced therapeutic dose for 3-6 months (class B recommendation).

If long-term LMWH therapy cannot be used or is contraindicated in patients with malignancy-associated VTE, suggested alternative options include use of oral VKA (class $B$ recommendation) or oral direct factor $X a$ and factor Ila inhibitors (except in patients receiving chemotherapy) (class $\mathrm{C}$ recommendation).

In all patients receiving anticoagulation for malignancy-associated VTE, periodic (every 2-3 months) reevaluation of the bleeding risk and the potential benefit-to-risk ratio for continuing anticoagulation is recommended, taking into account patient preferences (class $\mathrm{C}$ recommendation).
In patients with malignancy-associated VTE, continuation of anticoagulation is suggested until the risk of major bleeding exceeds potential benefits of this therapy (class $\mathrm{C}$ recommendation).

\section{Management of venous thromboembolism in patients with renal failure}

In patients with renal dysfunction with significantly reduced GFR ( $<30 \mathrm{~mL} / \mathrm{min}$ ), UFH may be used relatively safely in full therapeutic doses (guided by APTT measurements).

Of note, if full anticoagulation is required in patients with severe renal failure, UFH should be chosen as the anticoagulant drug in most situations, taking into account its benefit-to-risk ratio compared to LMWH, and the established effectiveness of protamine sulphate as an antidote in patients receiving UFH.

The approach to the management of DVT and hemodynamically stable PE using UFH and VKA is the same as in patients with normal renal function (class $A$ recommendation).

In patients with renal dysfunction and the estimated glomerular filtration rate (eGFR) of $30-40 \mathrm{~mL} / \mathrm{min}$ (assessment of eGFR should be repeated every I-2 months during stable periods and every several days during periods of renal failure exacerbation), chronic LMWH therapy in reduced doses adjusted for anti-Xa activity is acceptable, optimally with repeated regular assessment of anti-Xa activity (class $C$ recommendation). Use of oral direct factor $\mathrm{Xa}$ and factor Ila inhibitors is not recommended in patients with eGFR $<30 \mathrm{~mL} / \mathrm{min}$.

\section{Prevention of postthrombotic syndrome using compression products}

\section{Recommendations}

We recommend use of compression products in all patients with a DVT episode and concomitant postthrombotic syndrome and/or chronic venous disease (class $\mathrm{C}$ recommendation).

Use of compression products in patients with acute DVT without symptoms of postthrombotic syndrome and/or chronic venous disease is controversial due to inconsistent research results [45-48].

However, the authors of PCS 2017 recommend use of compression products in patients with acute DVT without symptoms of postthrombotic syndrome as a method to prevent the latter (class $\mathrm{Cl}$ recommendation). This recommendation stems from a comprehensive analysis of the available research data and not only findings of a single study that did not show benefits from the use of compression products in patients with DVT without symptoms of postthrombotic syndrome [47]. 


\section{Management of venous thromboembolism} recurrence during anticoagulant therapy

In patients with VTE recurrence during anticoagulation with VKA (with INR in the range of 2-3), factor $X a$ inhibitors (apixaban, edoxaban, rivaroxaban), factor lla inhibitors (dabigatran), or sulodexide used for extended secondary VTE prevention, previous anticoagulant therapy needs to be switched to LMWH in therapeutic doses.

In these settings, the duration of treatment with therapeutic dose LMWH recommended in the 2016 ACCP guidelines is one month [I]. Such a therapeutic decision must be preceded by a careful analysis of the criteria for VTE recurrence (new contrast filling defects in CT pulmonary angiography or perfusion defects in perfusion lung scintigraphy, increase in the thickness of a previously imaged thrombus by $4 \mathrm{~mm}$, appearance of a thrombus in a new vein, identification of proximal thrombus propagation) and an analysis of previous anticoagulant therapy (patient cooperation, maintaining INR in the range of 2-3, compliance with the prescribed dosing regimen). If thrombosis recurs during an adequately managed anticoagulant therapy, consider a possibility of concomitant asymptomatic and unrecognized malignancy.

Recurrent VTE in patients receiving chronic LMWH treatment used as long-term anticoagulant therapy or for extended secondary VTE prevention requires modification of LMWH treatment. Administer therapeutic LMWH dose if the patient was on a lower dose, followed by chronic LMWH dose increase by 25-30\%. In patients with recurrent VTE while on a therapeutic LMWH dose, increase the LMWH dose by $25 \%$ and administer LMWH twice daily (if previously administered once daily) or use UFH in continuous infusion. An increased therapeutic LMWH dose should be administered for one month and then reduced [ $\mathrm{I}$. In selected cases, measurement of anti-Xa activity is indicated.

\section{Recommendations}

In case of VTE recurrence during an adequately managed anticoagulant therapy, previous anticoagulant therapy needs to be switched to LMWH. LWMH should be administered in a therapeutic dose continued for at least one month (class $B$ recommendation).

Recurrent $V T E$ in patients receiving chronic $L M W H$ treatment used as long-term anticoagulant therapy or for extended secondary VTE prevention requires modification of LMWH treatment. Administer therapeutic LMWH dose if the patient was on a lower dose, followed by chronic LMWH dose increase by $25-30 \%$.

In patients with recurrent VTE while on a therapeutic LMWH dose, increase the LMWH dose by
$25 \%$ and administer LMWH twice daily (if previously administered once daily) or use UFH in continuous infusion. An increased therapeutic LMWH dose should be administered for one month and then reduced (class $B$ recommendation). Measurement of anti-Xa activity may be useful to evaluate the effectiveness of LMWH treatment.

\section{Thrombolysis and interventional treatment of pulmonary embolism}

While indications for thrombolysis in PE are quite well defined, interventional treatment of $P E$ is controversial. Little research evidence is available to evaluate the safety and efficacy of various interventions, and study findings are inconsistent [I, 21, 22, 49-52].

\section{Recommendations}

Patients with acute $P E$ associated with significant hypotension (systemic systolic blood pressure $<90 \mathrm{~mm} \mathrm{Hg}$ for 15 minutes) or shock should receive systemic thrombolytic therapy if the bleeding risk is not high (class A recommendation).

Thrombolytic therapy is not recommended during acute treatment of PE without hypotension or shock (class A recommendation).

In patients with acute PE and worsening of vital parameters without evidence of shock or systemic blood pressure fall (increased heart rate and breathing rate, distended jugular veins, fall in oxygen saturation, cold sweating, pallor, reduction of minute by minute urine output, worsening right ventricular dysfunction by echocardiography, increasing biomarker levels), systemic thrombolytic therapy should be considered following initial anticoagulation (class $\mathrm{C}$ recommendation).

Catheter-directed thrombolysis as initial therapy in patients with acute PE remains controversial and is currently not recommended (class $\mathrm{Cl}$ recommendation).

Interventional treatment of acute PE to improve pulmonary artery flow (catheter-directed thrombolysis or pulmonary artery thrombectomy without thrombolysis) using various technologies is reserved for acute PE with hypotension and cases with a high bleeding risk and following ineffective systemic thrombolysis (class $C$ recommendation).

\section{Chronic thromboembolic pulmonary hypertension}

Chronic thromboembolic pulmonary hypertension (CTEPH) is a rare consequence of PE due to chronic pulmonary artery obstruction by organized thrombi $[I, 5 I]$. The incidence of CTEPH following PE has been estimated at about 3-4\%. Unrecognized CTEPH not only leads to reduced quality of life but may also result in death. Major risk factors include recurrent idiopathic 
$\mathrm{PE}$, large thrombus burden, right ventricular overload during acute $\mathrm{PE}$, and initiation of anticoagulation delayed beyond 2 weeks since the onset of PE symptoms. The initial symptom of CTEPH is dyspnea on exertion, while right ventricular heart failure develops only at an advanced disease stage. Routine investigations for $\mathrm{CTEPH}$ in all patients following an acute PE event are currently not recommended. CTEPH should be suspected in PE patients with persisting exertional dyspnea or limited exercise tolerance (compared to the period before acute PE event) despite effective anticoagulation for at least 3 months. The recommended screening tool is echocardiography, and patients with evidence of right ventricular overload should be referred to tertiary care centers for further investigations and management of CTEPH. The definite diagnosis of CTEPH is based on pulmonary arteriography and right heart catheterization findings.

\section{Recommendations}

Routine investigations for CTEPH in all patients following an acute PE event are not recommended. Echocardiography to detect right ventricular overload is recommended in PE patients with persisting limited exercise tolerance despite anticoagulation for 3 months. The treatment of choice is pulmonary thrombendarterectomy (class $\mathrm{B}$ recommendation).

If surgery is contraindicated or thrombi are located distally, patients may be treated with balloon pulmonary angioplasty (class $C$ recommendation) and/or pharmacologically with riociguate, a soluble guanylate cyclase agonist (class B recommendation). Regardless of these therapies, patients with CTEPH require lifelong anticoagulation (class $\mathrm{B}$ recommendation).

\section{Thrombolytic therapy of proximal lower and upper limb deep venous thrombosis}

Catheter-directed thrombolysis may be considered in proximal DVT, in particular iliofemoral thrombosis in young patients at low bleeding risk, because the risk of chronic venous disease in these patients is higher compared to more distal DVT [I]. Systemic thrombolysis should be avoided. Similar approach should govern the choice of therapy in young patients with axillary vein thrombosis or more proximal upper limb deep vein thrombosis [I].

The following factors favor the decision to proceed with catheter-directed thrombolysis:

- symptom duration less than 14 days;

- overall good patient status;

- low bleeding risk;

- expected survival more than one year;

- an experienced and well-trained team performing the procedure [I].
In patients with acute proximal upper or lower limb DVT, anticoagulation remains the primary treatment approach favored over cathether-directed thrombolysis [I]. It should be noted that both the intensity and duration of anticoagulation must follow the general management principles regardless of whether the patient received or did not receive thrombolytic treatment [I].

\section{Recommendations}

We suggest considering catheter-directed thrombolysis in young patients at low bleeding risk with proximal DVT (particularly iliofemoral thrombosis and upper limb DVT involving the axillary vein and more proximal veins) (class $C$ recommendation).

\section{Surgical thrombectomy}

Surgical venous thrombectomy should be considered in patients with symptomatic iliofemoral DVT who are not candidates to catheter-directed thrombolysis (class $\mathrm{C}$ recommendation).

\section{Mechanical transcatheter interventions}

Percutaneous mechanical thrombectomy is currently used to dissolve, fragment, and aspirate thromboembolic material in patients with acute massive DVT or PE. This method is best used for the treatment of fresh thrombi (less than 10- to 14-days-old). Its effectiveness in more chronic thromboembolic disease is less predictable. No clear data are available regarding the short- and long-term effect of mechanical transcatheter interventions on the vessel wall, venous valves, and pulmonary vessels. More reliable research evidence is necessary to establish the role of this approach. This technique requires further evaluation in short- and longterm studies, including randomized controlled clinical trials, before any recommendations can be made.

\section{Inferior vena cava filters}

Implantation of inferior vena cava filters remains controversial. However, most experts believe that indications for implantation of permanent, temporary, and removable filters are limited [53-60].

\section{Recommendations}

Implantation of removable inferior vena cava filters is indicated in patients with PE and proximal DVT in whom contraindications to anticoagulation exist or complications have developed that preclude continuation of anticoagulant therapy (class $B$ recommendation).

Filter implantation is not recommended in patients with acute proximal DVT or PE who receive anticoagulant therapy (class A recommendation).

Implantation of an inferior vena cava filter should be considered in case of recurrent VTE related to malig- 
nancy in patients receiving increased LMWH doses (by $25 \%$ compared to usual therapeutic doses) in whom reversible risk factors for VTE recurrence are not present and LMWH dose cannot be increased (class $\mathrm{C}$ recommendation).

\section{Complications of anticoagulant therapy}

The most important complication associated with the use of heparins, VKA, factor Xa inhibitors, factor Ila inhibitors and other anticoagulants is bleeding. It has been estimated that serious internal bleeding that requires immediate in-hospital management, such as gastrointestinal bleeding, retroperitoneal hematoma, or intracranial bleeding, occurs in about $5 \%$ of patients receiving therapeutic heparin doses and $2-3 \%$ of patients on long-term VKA therapy.

Bleedings are most common in the elderly, those with multiple comorbidities (e.g., malignancy, renal failure, peptic ulcer disease), patients receiving drugs that impair hemostasis (e.g., NSAID, antiplatelet drugs, etc.), and in those patients in whom anticoagulant therapy is not monitored adequately. Bleeding may also be a result of an invasive diagnostic procedure or surgery if anticoagulant doses are not adjusted to the clinical settings. The incidence of bleeding complications increases with the duration of anticoagulant therapy.

In patients receiving VKA in whom INR is in the range of 2.0-3.0, the risk of severe bleeding is more than $50 \%$ lower compared to patients with INR > 3.0. Rapid (essentially immediate) neutralization of the anticoagulant effect of VKA is possible following administration of prothrombin complex concentrate (PCC). Fresh frozen plasma, which contains prothrombin complex clotting factors (II, VII, IX, and X), also normalizes INR in patients treated with VKA. It should be stressed, however, that the effectiveness of fresh frozen plasma is lower compared to that of PCC.

Of note, intravenous or oral vitamin $\mathrm{K}$ administration contributes to INR lowering or even normalization but only after several hours.

Use of fondaparinux, UFH, or LMWH for acute VTE treatment is associated with a similar risk (I.I-I.3\%) of major bleeding.

Other adverse effects of heparins, including mild hypoaldosteronism, transient increase in serum aminotransferase [aspartate aminotransferase (AST) and alanine aminotransferase (ALT)] activity, allergic reactions, and transient hair loss, are not indications to withdraw heparin or institute additional therapy. UFH or LMWH use for more than 3 months in a daily dose of 20,000 IU or 20,000 anti-Xa units, respectively, is associated with a risk of osteoporosis. Studies indicate that the risk of osteoporosis is lower with LMWH compared to UFH use. Issues related to heparin-induced thrombocytopenia (HIT) are discussed in a separate chapter.

VKA therapy is very rarely associated with such adverse effects as skin allergic reactions, cold intolerance, priapism, thyroid cartilage calcification, and purple toes syndrome.

A benign but somewhat more common complication that is poorly acceptable by patients receiving VKA is excessive hair loss. Skin necrosis is a rare but very dangerous complication of VKA therapy. It usually occurs at 3- I 0 days of VKA administration. Skin necrosis results from thrombosis within small veins and capillaries in the subcutaneous fat tissue of the buttocks, thighs, genitals, chest, face, and upper limbs. The underlying abnormality is a paradoxical hypercoagulability state resulting from rapidly decreasing activity of protein $\mathrm{C}$, a vitamin K-dependent natural clotting inhibitor with a biological half-life of only about 6 hours. Congenital protein $\mathrm{C}$ and protein $\mathrm{S}$ deficiencies predispose to the development of skin necrosis.

Use of oral factor Xa inhibitors (apixaban, edoxaban, rivaroxaban) and factor II inhibitors (dabigatran) is associated with much higher treatment safety compared to VKA (due to much lower rates of bleeding complications). This is particularly evident for intracranial bleeding.

The only antidote licensed for use in clinical practice is available for dabigatran. This antidote is idarucizumab, a humanized antibody administered intravenously in a $5 \mathrm{~g}$ dose when indicated [6I]. The anticoagulant effect of dabigatran is rapidly reversed following idarucizumab administration.

An antidote that immediately neutralizes the anticoagulant effect of factor $\mathrm{Xa}$ inhibitors and LMWH is being developed. Studies evaluating the efficacy and safety of adnexanet-alfa, a recombinant protein neutralizing the effect of all factor $\mathrm{Xa}$ inhibitors and $\mathrm{LMWH}$, are currently at an advanced stage and are expected to be completed soon $[62,63]$.

\section{Management of bleeding and other complications resulting from UFH or LMWH use}

\section{Recommendations}

In case of major bleeding, administration of UFH/ LMWH should be discontinued immediately (class $A$ recommendation). Discontinuation of intravenous UFH infusion leads to drug elimination from the bloodstream within several dozen minutes. If the anticoagulant effect of UFH needs to be reversed immediately, a heparin-neutralizing agent protamine sulphate is given intravenously (class B recommendation). The maximum protamine sulphate dose may not exceed $50 \mathrm{mg}$, and the rate of injection should not be higher than $5 \mathrm{mg} / \mathrm{min}$. Rapid administration of protamine sulphate may result in a decrease in blood pressure and heart rate. As the 
duration of LWMH elimination from the body following its subcutaneous injection is much longer compared to elimination of UFH given intravenously, protamine sulphate neutralizes LMWH weaker than UFH.

Low-molecular-weight heparins are eliminated via kidneys, and thus in patients with renal failure with eGFR $<30 \mathrm{~mL} / \mathrm{min}$ who require therapeutic heparin doses, APTT-guided UFH therapy is preferred (class $\mathrm{C}$ recommendation). If $\mathrm{LMWH}$ are used in this patient group, their doses need to be reduced and treatment should be guided by anti-Xa activity measurements (class $C$ recommendation).

In patients receiving long-term therapy with high heparin doses, use of calcium supplements and alphacalcidol should be considered to reduce the risk of osteoporosis (class $\mathrm{C}$ recommendation). If heparin has been administered for more than one year, bone mineral density studies are indicated every 12 months until heparin treatment is discontinued (class $\mathrm{Cl}$ recommendation). If reduced bone mineral density is found in a subject who requires continued heparin therapy, initiation of alendronate is suggested (class $\mathrm{Cl}$ recommendation).

\section{Management of bleeding and other} complications resulting from VKA and oral direct factor $\mathrm{Xa}$ and factor Illa inhibitor use

In case of major bleeding during VKA therapy, the drug should be discontinued immediately and vitamin $\mathrm{K}$ (5-10 mg) should be administered intravenously, followed, if necessary, by administration of PCC 25-50 units $/ \mathrm{kg}$ body weight or transfusion of fresh frozen plasma (the latter treatment is less effective) (class $C$ recommendation).

If the bleeding is life-threatening, intravenous administration of recombinant active factor VII ( $\mathrm{rFVlla}$ ) should be considered (class $C$ recommendation).

In case of VKA-induced skin necrosis, VKA should be discontinued immediately and UFH should be administered intravenously, followed by LMWH at a therapeutic dose (class $\mathrm{C}$ recommendation). Intravenous vitamin $\mathrm{K}$ and fresh frozen plasma should also be administered (class $\mathrm{C}$ recommendation). Reinstitution of VKA therapy is possible but with concomitant heparin administration for 10-14 days at a therapeutic dose and initiation of VKA therapy in very low doses (e.g. warfarin 3-5 mg per day or acenocoumarol I-2 mg per day for the first 3-4 days, followed by small dose increases until achieving and maintaining INR in the therapeutic range) (class $\mathrm{C}$ recommendation). In case of VKA-induced skin necrosis, oral direct factor $\mathrm{Xa}$ and factor lla inhibitors (rivaroxaban and dabigatran) may be considered for chronic therapy.
Dihydroxycoumarin derivatives are contraindicated during pregnancy (due to a teratogenic effect) but may be used during lactation as they do not pass into human milk (class $B$ recommendation). (Note: Due to their higher safety, VKA are recommended during pregnancy - except for the first trimester - in patients with valve prosthesis [risk of valve thrombosis]).

In case of major bleeding during oral factor $\mathrm{Xa}$ or factor Ila inhibitor therapy, these drugs should be discontinued immediately [64]. In case of a life-threatening bleeding associated with dabigatran therapy, idarucizumab administration is indicated (class $B$ recommendation). If a major or life-threatening bleeding is associated with factor $\mathrm{Xa}$ inhibitor therapy (apixaban, edoxaban, rivaroxaban, administration of PCC, activated PCC (aPCC) or fresh frozen plasma (the latter treatment is less effective) should be considered (class C recommendation).

Currently, no antidote is available in clinical practice that might reverse the anticoagulant effect of fondaparinux (protamine sulphate does not neutralize fondaparinux). In case of major bleeding, it is recommended to discontinue fondaparinux, correct anemia with packed red blood cell transfusions, and in case of a life-threatening bleeding, consider administration of $\mathrm{rFVIla}$ (class $\mathrm{C}$ recommendation). A potential antidote that neutralizes the anticoagulant effect of fondaparinux is adnexanet alfa $[62,63]$.

\section{Heparin-induced thrombocytopenia (HIT)}

Heparin-induced thrombocytopenia is an important adverse effect of heparins. Development of HIT has been reported in $1 \%$ of medical patients, $3 \%$ of patients after surgical procedures, and $5 \%$ of patients undergoing cardiac surgical procedures and orthopedic surgical procedures but this condition has also been diagnosed in other patient populations. The most severe complication, seen in about one third of patients with HIT, is progression to overt thrombosis which may result in amputation or death. Thrombosis may involve any venous or arterial vessels. As spontaneous bleedings and petechiae have been reported very rarely, it must be noted that HIT is not a bleeding diathesis.

Heparin-induced thrombocytopenia develops as a result of exposure to UFH administered in prophylactic and therapeutic doses or used for other purposes (e.g., for catheter flushing). LMWH also cause HIT but at a 2- to 3-fold lower rate compared to UFH. It seems that the incidence of HIT has decreased due to lower use of UFH and higher use of LMWH and other anticoagulant drugs. Preventive measures include administration of LMWH or fondaparinux instead of UFH for thromboprophylaxis following surgical procedures, choosing 
porcine and not bovine UFH, and avoiding unnecessary and prolonged exposure to UFH.

In patients receiving current or recent heparin therapy, HIT should be suspected if the platelet count has been reduced by $30 \%$ compared to baseline and no other reasons for thrombocytopenia exist. The diagnosis can be made if the platelet count has been reduced by $50 \%$ compared to baseline without other reasons for thrombocytopenia. Absolute thrombocytopenia does not have to be present in patients with HIT, i.e., the platelet count does not have to be reduced below $100,000 / \mu \mathrm{L}$ (e.g., reduction from $350,000 / \mu \mathrm{L}$ to $175,000 / \mu \mathrm{L})$. Characteristic features of HIT also include rapid platelet count reduction without other reasons and unexplained thrombosis. Symptoms usually occur at 4-14 days since exposure to UFH or 8-14 days since exposure to $\mathrm{LMWH}$. In patients who received heparin within the last 100 days, immediate HIT may develop following repeated administration of UFH or LMWH. Delayed-onset HIT has also been observed, with symptoms occurring several days after discontinuation of UFH. The diagnosis should be confirmed with laboratory tests, for example by measuring antibodies to heparin-platelet 4 complex.

\section{Recommendations}

Early diagnosis and treatment of HIT is of major importance for improving clinical outcomes. The diagnosis of HIT is based on comprehensive interpretation of clinical and laboratory data.

During the first 14 days of treatment, platelet count should be evaluated every $3-5$ days in patients receiving $\mathrm{LMWH}$, more frequently in patients receiving $\mathrm{UFH}$, and daily if the risk of $\mathrm{HIT}$ is high (class $\mathrm{C}$ recommendation).

In medical and obstetrical patients receiving only prophylactic LMWH doses, without previous exposure to UFH, platelet count monitoring is not considered obligatory.

All clinical units, including emergency rooms and departments, should be made aware of the diagnosis of HIT in a patient, and of previous exposure to UFHLMWH.

In case of a serious suspicion of HIT, appropriate laboratory tests should be performed (measurement of antibodies to heparin-platelet 4 complex). These tests do not serve to confirm the diagnosis of HIT but their negative results exclude this diagnosis with a high degree of certainty. Thus, therapeutic decisions in case of HIT should not depend on a positive result of testing for antiheparin antibodies but on the overall clinical picture (thrombocytopenia and/or new thromboembolic events).

In case of suspected or diagnosed HIT, administration of UFH and LMWH should be discontinued (class A recommendation) but discontinuation of heparin itself is not sufficient. Due to a severe hypercoagulability state and a high risk of thrombosis associated with HIT it is recommended to treat all HIT patients with an anticoagulant other than heparin, such as argatroban, lepirudin, danaparoid, or fondaparinux, and if these drugs are not available, oral factor Ila or factor $\mathrm{Xa}$ inhibitor should be used (class $C$ recommendation). When making clinical decisions regarding therapy, differences between these drugs should be taken into account, including such factors as renal or hepatic drug elimination, drug pharmacokinetics, individual patient bleeding risk, previous patient exposure to lepirudin, physician's experience with a given drug, drug availability, immune cross-reactivity with antibodies present in HIT and so forth. If danaparoid is used for the treatment of HIT and the platelet count does not increase within the first 3 days of treatment, it is necessary to check for cross-reactivity of danaparoid with the antibodies present in the patient using a functional platelet assay, and this treatment should be discontinued if a positive test result is obtained. $\mathrm{LMWH}$ are contraindicated in patients with HIT (class A recommendation).

Vitamin $\mathrm{K}$ antagonists may be used for long-term anticoagulant therapy in patients with a history of HIT. To avoid limb gangrene or skin necrosis induced by VKA, these drugs are administered to patients with HIT only after platelet count increases to more than $100,000 / \mu \mathrm{L}$ or to the baseline value before the occurrence of HIT (class $\mathrm{C}$ recommendation). Initial dose should be small (e.g., warfarin $5 \mathrm{mg}$ or acenocoumarol $4 \mathrm{mg}$ ) and administered concomitantly with argatroban, lepirudin, danaparoid, or fondaparinux for at least 5 days. In special groups of HIT patients who require anticoagulation, such as pregnant women, children and patients undergoing coronary intervention, other vascular procedures, cardiac surgical procedures or hemodialysis, specific factors regarding the drug choice and dose selection should be taken into account.

\section{Education of patients treated with vitamin $\mathrm{K}$ antagonists}

Proper use of VKA is a particularly important aspect of anticoagulant therapy which poses many problems in everyday clinical practice. It has been estimated that nearly $1 \%$ of the general population in the developed countries is anticoagulated with VKA. Unfortunately, as many as about $3 \%$ of them are hospitalized each year due to bleeding complications. Adverse effects of VKA are the most common drug-related cause for hospital admission among all complications of pharmacotherapy. When the most common strategy of follow-up INR measurements and visits to a family physician every 3-6 weeks is employed, only $40-60 \%$ 
of INR measurements are within the desired range (2.0-3.0). Therapy with VKA cannot be limited to drug prescription and a recommendation of periodic follow-up INR measurements. Optimization of VKA treatment effectiveness and safety must be achieved by meticulous compliance with current management standards along with use of home INR monitors and software to optimize VKA dosing.

Due to continuingly high number of patients treated with VKA and an increasing number of patients treated with novel anticoagulants, it is reasonable to increase the number of dedicated anticoagulation clinics. Their purpose is to coordinate and optimize anticoagulant therapy to improve the benefit-to-risk ratio of anticoagulation.

The effectiveness and safety of chronic anticoagulation is largely dependent on informed and active involvement on the part of the patient and his/her family. For this reason, patient education must be undertaken according to a program that allows transfer of necessary information and acquisition of useful practical skills. Assimilation of this information is necessary not only for the patient but also for healthcare personnel and family members caring for the anticoagulated patient. The following information should be included in the education process:

- types of anticoagulant drugs;

- indications for anticoagulation and related benefits and risks;

- nature of the clotting process;

- nature and desired extent of the effect of anticoagulants on the clotting system;

- therapeutic INR range;

- importance or regular laboratory monitoring;

- need to run an anticoagulation therapy diary;

- effect of concomitant therapies;

- effect of nutrition;

- management in case of bleeding, surgery, and pregnancy;

- management in case of acute illness and omitting a drug dose;

- leisure activities and anticoagulation.

The scope of education may also be extended to include patient self-management skills related to the use of personal INR monitor with dedicated computer software to determine the individual dose of oral anticoagulant and the next scheduled anticoagulant dose adjustment.

\section{Principles of bridging long-term VKA therapy with LMWH or UFH}

Due to a risk of bleeding complications related to VKA therapy in patients undergoing invasive diagnostic and therapeutic procedures (particularly in patients who require surgery), modification of previous anticoagulant therapy is usually required. The proposed management should include both the risk of possible bleeding complications related to the planned procedure and the risk of thromboembolic complications (including recurrent VTE) in case of VKA withdrawal or dose reduction. Patients at high risk of recurrent VTE include those with a VTE event within the last 3 months, patients with VTE related to a malignancy, patients with severe thrombophilias (antithrombin, protein C, or protein $\mathrm{S}$ deficiency, antiphospholipid syndrome, and combined thrombophilias), and other clinical situations associated with persistent significant risk factors for VTE recurrence. Patients at low risk of recurrent VTE are likely those with a single VTE event $>12$ months earlier, but it should be remembered that the risk of DVT or PE recurrences remains permanently elevated in some of such patients, particularly those with idiopathic venous thrombosis and patients in whom incomplete deep vein recanalization is found in a follow-up ultrasonography performed at the end of the planned period of extended secondary VTE prevention. The remaining patients who do not fit to either of the above categories are at moderate risk of recurrent VTE.

Few randomized clinical trials are available to guide class $A$ recommendations regarding the perioperative management of anticoagulation in patients treated with VKA. Recommendations have been based on little available evidence from randomized studies, experience of the experts, and prospective clinical studies performed in small patient groups.

\section{Recommendations}

In patients at low risk of VTE recurrence, we suggest interrupting VKA therapy before the planned procedure ( 3 days before in case of acenocoumarol therapy and 5 days before in case of warfarin therapy), which allows near-normalization of INR on the day of surgery. If INR is still > 1.5 on the day before surgery, oral administration of vitamin $\mathrm{K}(\mathrm{I}-2 \mathrm{mg})$ is recommended. Due to an increased risk of VTE recurrence related to the previous VTE event, use of prophylactic LMWH or UFH doses is suggested in the pre- and postoperative period until therapeutic INR values are achieved (acenocoumarol or warfarin therapy should be initiated when adequate hemostasis is obtained after the surgery) (class $\mathrm{Cl}$ recommendation).

In patients at high risk of VTE recurrence, we recommend interrupting VKA therapy before the planned procedure ( 3 days before in case of acenocoumarol therapy and 5 days before in case of warfarin therapy) and initiating LMWH subcutaneously at $50-100 \%$ of the therapeutic dose or therapeutic dose UFH (as intravenous infusion). Intravenous UFH infusion should be 
stopped about 4-5 hours before the planned procedure. Due to a possibility of a persisting effect of therapeutic dose LMWH in the perioperative period with twice daily LMWH dosing, we suggest administering the last LMWH dose 24 hours before the procedure. If therapeutic dose $\mathrm{LMWH}$ is administered once daily, we recommend administering the last $\mathrm{LMWH}$ dose 24 hours before the procedure and reducing it by $50 \%$ (class $C$ recommendation). After the procedure, intravenous UHF infusion or therapeutic dose LMWH should be reinitiated as soon as possible when adequate hemostasis is achieved (class $C$ recommendation). In patients undergoing minor surgical procedures or other invasive procedures associated with a low risk of bleeding, interruption of previous anticoagulant therapy is not recommended. It is indicated to lower VKA treatment intensity to INR of 2 . In patients at high risk of bleeding in the postoperative period, it is recommended to delay reinitiation of therapeutic dose LMWH to 48-72 hours after the procedure (provided that adequate hemostasis is achieved; if adequate hemostasis is not achieved, management should be guided by the assessment of benefits from anticoagulation and the risk of complications: options include temporary withdrawal of anticoagulation or use of prophylactic LMWH or UFH doses) (class $C$ recommendation).

In patients at moderate risk of VTE recurrence, we recommend interrupting VKA therapy before the planned procedure ( 3 days before in case of acenocoumarol therapy and 5 days before in case of warfarin therapy) and using therapeutic or prophylactic LMWH or UFH doses. If therapeutic doses are chosen, patients should be managed similarly to those at high risk of thromboembolic complications (class $\mathrm{C}$ recommendation).

If prophylactic doses are chosen (UFH 5000 IU subcutaneously three times daily or prophylactic dose LMWH), they should be initiated when INR is lowered to $<2$. In the postoperative period, patients receiving therapeutic UFH or LMWH doses should be managed similarly to high risk patients. If prophylactic UFH or LMWH doses are used, they should be continued postoperatively (provided that adequate hemostasis is achieved) and VKA therapy should be reinitiated, with prophylactic LMWH or UFH doses used until therapeutic INR values are achieved (class $C$ recommendation).

Due to a risk of thromboembolic complications in patients at high or moderate VTE risk, when therapeutic dose LMWH is discontinued in the period immediately before and after a surgical procedure, administration of a prophylactic LMWH dose in the immediate perioperative period should be always considered (until adequate hemostasis is achieved and therapeutic dose $\mathrm{LMWH}$ is reinitiated) (class $\mathrm{C}$ recommendation).
In case of procedures associated with a low risk of bleeding and VTE recurrence, we suggest reducing VKA dose (acenocoumarol 2-3 days before the procedure, warfarin 4-5 days before the procedure) to achieve INR $<$ I.5. Following the procedure, VKA dose should be increased until therapeutic INR values are achieved, if necessary combined with administration of prophylactic UFH or LMWH doses (as mentioned above, the latter approach does not apply to patients at high or moderate risk of VTE recurrence) (class $C$ recommendation).

In case of dental procedures which require only local control of bleeding (INR should always be measured before the procedure so as to verify whether it is within the therapeutic range), local administration of hemostatic agents without interrupting VKA therapy is recommended (class $C$ recommendation). In case of extensive dental procedures or maxillofacial surgical procedures associated with a high bleeding risk, we suggest that the management should be guided by the risk of VTE recurrence, as outlined above (class $\mathrm{C}$ recommendation).

\section{Management in case of elective and urgent} surgical procedures in patients receiving oral direct factor $\mathrm{Xa}$ and factor Ila inhibitors

If a surgical procedure - either urgent or elective - is planned in a patient treated with apixaban, edoxaban, rivaroxaban or dabigatran, the following parameters should be known:

- elimination half-time of the drug used;

- patient eGFR,

- duration of treatment;

- current prothrombin time (factor Xa inhibitors), APTT (factor lla inhibitors);

- platelet count;

- other medications taken by the patients (particularly P-glycoprotein inhibitors or agonists) [64].

The SPC of each drug includes manufacturer information about the optimal timing of anticoagulant withdrawal before a planned surgical procedure, taking into account the above factors.

The timing of anticoagulant withdrawal before the planned procedure depends on the assessment of VTE recurrence risk and other factors discussed above. LMWH use in the periprocedural period depend on the risk of VTE recurrence and the risk of bleeding complications.

If an urgent surgical procedure is needed in a patient treated with dabigatran, a specific antidote (idarucizumab) may be administered to reverse the anticoagulant effect of dabigatran [6I].

In patients treated with oral direct factor Xa inhibitors, immediate reduction of anti-Xa activity to reverse the anticoagulant effect of these drugs is not possible. In such cases, the management should include: 
- delaying an urgent procedure, if possible;

- charcoal administration, if the anticoagulant drug was ingested recently (within 2 hours);

- obtaining adequate amounts of PCC or aPCC before the procedure, so as to be able to administer it immediately in case of a major bleeding (PCC administration before the procedure may also be considered);

- provision of adequate amounts of blood products to be transfused as needed, including platelets if necessary.

\section{Management of central venous obstruction at} the level of inferior vena cava and iliac veins

Central venous obstruction at the level of inferior vena cava and iliac veins following DVT results in very high intravenous pressures and is associated with the most severe clinical course of the postthrombotic syndrome.

High effectiveness of intravascular recanalization procedures with stenting has been reported in multiple studies, with a high patency rate during further follow-up. An increasing number of intravascular deep vein recanalization procedures with stenting is also reported in Poland. These procedures are performed both in the acute phase of thrombosis as an addition to thrombolysis and at a later stage, in case of persistent obstruction resulting in the development of postthrombotic syndrome [65-67].

Randomized studies to confirm the efficacy of invasive methods and guide the optimal choice of anticoagulant therapy following stent implantation have not been performed yet.

Early in-stent thrombosis occurs usually due to technical errors, with inadequate inflow to and outflow from the stented segment. Following technically successful intravascular recanalization, thrombotic complications in the treated segment occur in $1.5 \%$ of patients at 30 days, and in $3 \%$ of patients during further follow-up. For this reason, adequate anticoagulant therapy to prevent stent obstruction is vital.

As highlighted by guideline authors, due to unclear treatment outcomes, with reported complications and treatment failures, intravascular techniques should not be used routinely. Rather, they should be reserved for patients with symptoms of moderate to severe postthrombotic syndrome with a significant limitation of the functional status and quality of life [65-67]. At the same time, a high potential of intravascular revascularization techniques suggests they might be used more widely in selected experienced centers. In addition to high procedural standards, these centers should offer adequate follow-up programs with an option to perform secondary procedures to maintain long-term vessel patency.

\section{Recommendations}

In the perioperative period, we recommend use of therapeutic dose UFH or LMWH along with VKA for 10 days. Heparin should be withdrawn after INR values in the range 2.5-3.5 are achieved (Note: target INR in these settings is 3). Anticoagulation with VKA should be continued for at least 6 months (target INR 2.5-3.5). Usefulness of oral factor Xa or factor lla inhibitors within 6 months following implantation of venous stents has not been confirmed in clinical studies (their efficacy and safety for this indication is unknown) and thus raises a number of controversies.

Further anticoagulant therapy should be individualized depending on the extent of thrombosis, type of reconstruction, hemodynamic factors, and the presence of additional risk factors, e.g., thrombophilia.

Anticoagulant therapy should be combined with early ambulation and compression therapy.

\section{Supplement}

After the PCS 2017 consensus conference, results of the randomized EINSTEIN CHOICE study (conducted also in Poland) that evaluated the efficacy and safety of two rivaroxaban doses ( $20 \mathrm{mg}$ and $10 \mathrm{mg}$ once daily) versus acetylsalicylic acid $100 \mathrm{mg}$ in VTE patients who required extended VTE prevention were published [68]. Due to large practical importance and quality of these results, this study is discussed below.

The EINSTEIN CHOICE study included 3396 patients with objectively confirmed VTE who completed 6 to 12 months of anticoagulant therapy. Following this period, the patients were randomized to one of the three study arms that received rivaroxaban $10 \mathrm{mg}$ or $20 \mathrm{mg}$ or acetylsalicylic acid $100 \mathrm{mg}$. Study therapy (extended VTE prevention) was continued for 12 months. Clinically symptomatic recurrent VTE, including deaths due to PE (primary efficacy endpoint), occurred during extended VTE prevention in $1.2 \%$ of patients receiving rivaroxaban $10 \mathrm{mg}, 1.5 \%$ of patients receiving rivaroxaban $20 \mathrm{mg}$, and $4.4 \%$ of patients receiving acetylsalicylic acid $100 \mathrm{mg}$. Major bleeding complications (primary efficacy endpoint) occurred in $0.4 \%$ of patients receiving rivaroxaban $10 \mathrm{mg}, 0.5 \%$ of patients receiving rivaroxaban $20 \mathrm{mg}$, and $0.3 \%$ of patients receiving acetylsalicylic acid $100 \mathrm{mg}$.

The rate of clinically relevant nonmajor bleeding according to ISTH was $2 \%$ in patients receiving rivaroxaban $10 \mathrm{mg}, 2.7 \%$ in patients receiving rivaroxaban $20 \mathrm{mg}$, and $1.8 \%$ in patients receiving acetylsalicylic acid. Due to clinically significant bleeding complications, anticoagulant therapy was interrupted for more than 14 days in $1.1 \%$ of patients receiving rivaroxaban $10 \mathrm{mg}, 1.5 \%$ of patients receiving rivaroxaban $20 \mathrm{mg}$, and $\mathrm{I} . \mathrm{I} \%$ of patients receiving acetylsalicylic acid. 
The EINSTEIN CHOICE study findings showed that the risk of recurrent VTE during extended VTE prevention was significantly lower in patients who received rivaroxaban (regardless of its dose -10 or $20 \mathrm{mg}$ ) compared to those patients who received acetylsalicylic acid. The bleeding risk did not increase during the use of study drugs.

Of note, the reduced $10 \mathrm{mg}$ rivaroxaban dose was not used in patients who required, for various indications (e.g., severe hereditary and acquired thrombophilias), higher anticoagulant doses - recommended and licensed for long-term anticoagulant therapy [68].

It should also be noted that in patients recruited to the EINSTEIN CHOICE study, the risk of bleeding complications was not evaluated before randomization, and thus it is difficult to evaluate the potential effect of $10 \mathrm{mg}$ and $20 \mathrm{mg}$ rivaroxaban doses and $100 \mathrm{mg}$ acetylsalicylic acid dose on the rates of bleeding complications in patients at low or moderate bleeding risk, and particularly in those at high bleeding risk.

A retrospective analysis is planned to evaluate the effect of both rivaroxaban doses and acetylsalicylic acid on the rates of bleeding complications in these bleeding risk groups. Only after this analysis is available, it will be possible to develop a clear recommendation for rivaroxaban $10 \mathrm{mg}$ dose in patients at high risk of recurrent VTE (except for patients with, e.g., severe acquired and hereditary thrombophilias) and high bleeding risk.

It should also be noted that long-term anticoagulant therapy was continued for a longer period (6-12 months) than recommended in PCS 2017 (3 months).

Despite the above issues with interpretation of the EINSTEIN CHOICE study findings, it seems that in patients with idiopathic VTE (high risk of recurrent VTE) and low or moderate bleeding risk, rivaroxaban $10 \mathrm{mg}$ may be an effective and safe alternative to rivaroxaban $20 \mathrm{mg}$, and a more effective and equally safe alternative to acetylsalicylic acid for extended VTE prevention. It is difficult to evaluate clearly the safety of the reduced rivaroxaban dose in patients at high risk of bleeding.

Note: Rivaroxaban $10 \mathrm{mg}$ has not been formally licensed yet for extended VTE prevention in the European Union countries.

Recently - after the PCS 2017 manuscript has been prepared - new Polish guidelines on thromboprophylaxis in oncological patients, with particular emphasis on patients undergoing surgical treatment, have been released and published in the "Acta Angiologica" journal. The authors of PCS 2017 recommend using these guidelines in the everyday clinical practice in Polish hospitals [69].

\section{Acknowledgment}

The authors of PCS 2017 thank Professor Anetta Undas for help in preparing the final version of the present recommendations.

\section{References}

I. Kearon C, Akl EA, Ornelas J, et al. Antithrombotic Therapy for VTE Disease: CHEST Guideline and Expert Panel Report. Chest. 2016; 149(2): 315-352, doi: 10.1016/i.chest.2015.11.026, indexed in Pubmed: 26867832.

2. Risk of and Prophylaxis for Venous Thromboembolism in Hospital Patients. Phlebology. 1998; 13(3): 87-97, doi: 10.1177/026835559801300302.

3. Tomkowski WZ, Dybowska M, Kuca P, et al. AVTERS investigators. Effect of a public awareness campaign on the incidence of symptomatic objectively confirmed deep vein thrombosis: a controlled study. J Thromb Haemost. 2012; I0(I I): 2287-2290, doi: 10.1111/j.1538-7836.2012.04915.x, indexed in Pubmed: 22950807.

4. Agnelli G, Bolis G, Capussotti L, et al. A clinical outcome-based prospective study on venous thromboembolism after cancer surgery: the @RISTOS project. Ann Surg. 2006; 243(I): 89-95, indexed in Pubmed: 16371741.

5. Dainty L, Maxwell GL, Clarke-Pearson DL, et al. Cost-effectiveness of combination thromboembolism prophylaxis in gynecologic oncology surgery. Gynecol Oncol. 2004; 93(2): 366-373, doi: 10.1016/i.ygyno.2004.02.004, indexed in Pubmed: 15099947.

6. Greer I. Thrombosis in pregnancy: maternal and fetal issues. The Lancet. 1999; 353(9160): |258-|265, doi: 10.1016/s01406736(98)।0265-9.

7. Anticoagulant therapy during pregnancy. InPharma. 2013; I5(I): 8-8, doi: 10.1007/bf03288080.

8. Bates SM, Greer IA, Pabinger I, et al. American College of Chest Physicians. Venous thromboembolism, thrombophilia, antithrombotic therapy, and pregnancy: American College of Chest Physicians Evidence-Based Clinical Practice Guidelines (8th Edition). Chest. 2008; $133(6$ Suppl): $844 S-886 S$, doi: 10.1378/ chest.08-0761, indexed in Pubmed: 18574280.

9. Bates S, Middeldorp S, Rodger M, et al. Guidance for the treatment and prevention of obstetric-associated venous thromboembolism. Journal of Thrombosis and Thrombolysis. 2016; 4I(I): 92-128, doi: 10.1007/s | |239-0|15-1309-0.

10. Chan WS, Ginsberg JS. Management of venous thromboembolism in pregnancy. W: van Beek EJR, Büller HR, Oudkerk M (red.). Deep vein thrombosis and pulmonary embolism. Wiley-Blackwell, Chichester. ; 2009: 353-37I.

II. Bates SM, Ginsberg JS. How we manage venous thromboembolism during pregnancy. Blood. 2002; 100(10): 3470-3478, doi 10.1182/blood-2002-03-0965, indexed in Pubmed: 12393666.

12. Chmielewski D, Górecki A, Kusz D, et al. [Principles of prevention of venous thromboembolism in orthopedics and traumatology (updated on 02/I8/20I4)]. Ortop Traumatol Rehabil. 20I4; 16(2): 227-239, doi: 10.5604/15093492.1105250, indexed in Pubmed: 25041893.

13. Kim S, Bosque J, Meehan JP, et al. Increase in outpatient knee arthroscopy in the United States: a comparison of National Surveys of Ambulatory Surgery, 1996 and 2006. J Bone Joint 
Surg Am. 201I; 93(II): 994-1000, doi: 10.2106/JBJS.I.01618, indexed in Pubmed: 21531866.

14. van Adrichem RA, Nemeth B, Algra A, et al. POT-KAST and POT-CAST Group. Thromboprophylaxis after Knee Arthroscopy and Lower-Leg Casting. N Engl J Med. 2017; 376(6): 515-525, doi: $10.1056 /$ NEJMoa 1613303 , indexed in Pubmed: 27959702.

15. Falck-Ytter Y, Francis $\mathrm{C}$, Johanson $\mathrm{N}$, et al. Prevention of VTE in Orthopedic Surgery Patients. Chest. 20 I2; 14 I (2), doi: 10.1378/ chest. II-2404.

16. van Adrichem RA, Debeij J, Nelissen RG, et al. Below-knee cast immobilization and the risk of venous thrombosis: results from a large population-based case-control study. J Thromb Haemost. 2014; 12(9): 1461-1469, doi: 10.11|1/jth.12655, indexed in Pubmed: 25040873.

17. van Adrichem RA, Nelissen RG, Schipper IB, et al. Risk of venous thrombosis after arthroscopy of the knee: results from a large population-based case-control study. J Thromb Haemost. 2015; 13(8): |44|-1448, doi: 10.11 | |/jth. 12996, indexed in Pubmed: 25940206 .

18. Thorlund JB, Juhl CB, Roos EM, et al. Arthroscopic surgery for degenerative knee: systematic review and meta-analysis of benefits and harms. BMJ. 2015; 350: h2747, indexed in Pubmed: 26080045.

19. Cohen AT, Harrington RA, Goldhaber SZ, et al. APEX Investigators. Extended Thromboprophylaxis with Betrixaban in Acutely III Medical Patients. N Engl J Med. 2016; 375(6): 534-544, doi: 10.1056/NEJMoal 601747, indexed in Pubmed: 27232649.

20. Gibson CM, Chi G, Halaby R, et al. APEX Investigators. Extended-Duration Betrixaban Reduces the Risk of Stroke Versus Standard-Dose Enoxaparin Among Hospitalized Medically III Patients: An APEX Trial Substudy (Acute Medically III Venous Thromboembolism Prevention With Extended Duration Betrixaban). Circulation. 2017; 135(7): 648-655, doi: 10.116I/CIRCULATIONAHA.116.025427, indexed in Pubmed: 27881569.

21. Di Nisio M, van Es N, Büller HR. Deep vein thrombosis and pulmonary embolism. Lancet. 2016; 388(10063): 3060-3073, doi: 10.1016/S0140-6736(16)305|4-I, indexed in Pubmed: 27375038.

22. Konstantinides SV, Torbicki A, Agnelli G, et al. Management of Acute Pulmonary Embolism. Eur Heart J. 2014; 14: 3033 3069, doi: doi: 10.1093/eurhearti/ehu283., indexed in Pubmed: 2517334I.

23. Agnelli G, Buller HR, Cohen A, et al. AMPLIFY Investigators. Oral apixaban for the treatment of acute venous thromboembolism. N Engl J Med. 2013; 369(9): 799-808, doi: 10.1056/ NEJMoa 1302507 , indexed in Pubmed: 23808982.

24. Pignataro BS, Nishinari K, Cavalcante RN, et al. EINSTEIN Investigators, EINSTEIN-PE Investigators, EINSTEIN Investigators. Oral rivaroxaban for symptomatic venous thromboembolism. N Engl J Med. 2010; 363(26): 2499-25I0, doi: 10.1056/NEJMoal007903, indexed in Pubmed: $21|288| 4$.

25. Büller HR, Décousus H, Grosso MA, et al. Hokusai-VTE Investigators. Edoxaban versus warfarin for the treatment of symptomatic venous thromboembolism. N Engl J Med. 2013; 369(15): |406-14 I5, doi: 10. 1056/NEJMoa 306638 , indexed in Pubmed: 23991658.

26. Andreozzi GM, Bignamini AA, Davì G, et al. SURVET Study Investigators. Sulodexide for the Prevention of Recurrent Venous Thromboembolism: The Sulodexide in Secondary Prevention of Recurrent Deep Vein Thrombosis (SURVET) Study: A Multicenter, Randomized, Double-Blind, Placebo-Controlled Trial. Circulation. 2015; 132(20): 1891-1897, doi: 10.1161/CIRCULATIONAHA. II 5.016930, indexed in Pubmed: 26408273.

27. Agnelli G, Buller HR, Cohen A, et al. PLIFY-EXT Investigators. Apixaban for extended treatment of venous thromboembolism. N Engl J Med. 2013; 368(8): 699-708, doi: 10.1056/NEJMoal 20754I, indexed in Pubmed: 23216615.

28. Schulman S, Kearon C, Kakkar AK, et al. RE-MEDY Trial Investigators, RE-SONATE Trial Investigators. Extended use of dabigatran, warfarin, or placebo in venous thromboembolism. N Engl J Med. 2013; 368(8): 709-718, doi: 10.1056/NEJMoal II3697, indexed in Pubmed: 23425163.

29. Brighton TA, Eikelboom JW, Mann K, et al. ASPIRE Investigators. Low-dose aspirin for preventing recurrent venous thromboembolism. N Engl J Med. 2012; 367(2I): 1979-1987, doi: 10.1056/ NEJMoa |210384, indexed in Pubmed: 23/2|403.

30. Becattini C, Agnelli G, Schenone A, et al. WARFASA Investigators. Aspirin for preventing the recurrence of venous thromboembolism. N Engl J Med. 2012; 366(21): 1959-1967, doi: 10.1056/NEJMoa I I 14238, indexed in Pubmed: 22621626.

31. Kaatz S, Ahmad D, Spyropoulos AC, et al. Subcommittee on Control of Anticoagulation. Definition of clinically relevant non-major bleeding in studies of anticoagulants in atrial fibrillation and venous thromboembolic disease in non-surgical patients: communication from the SSC of the ISTH. J Thromb Haemost. 2015; 13(I I): 2119-2126, indexed in Pubmed: 26764429.

32. Prandoni P, Noventa F, Ghirarduzzi A, et al. The risk of recurrent venous thromboembolism after discontinuing anticoagulation in patients with acute proximal deep vein thrombosis or pulmonary embolism. A prospective cohort study in 1,626 patients. Haematologica. 2007; 92(2): 199-205, indexed in Pubmed: 17296569.

33. Prandoni P, Lensing AW, Cogo A, et al. The long-term clinical course of acute deep venous thrombosis. Ann Intern Med. 1996; 125(I): I-7, indexed in Pubmed: $\underline{8644983}$.

34. Schulman S, Granqvist S, Holmström M, et al. The duration of oral anticoagulant therapy after a second episode of venous thromboembolism. The Duration of Anticoagulation Trial Study Group. N Engl J Med. 1997; 336(6): 393-398, doi: 10.1056/ NEJMI 99702063360601 , indexed in Pubmed: 9010144.

35. Douketis J, Tosetto A, Marcucci M, et al. Does the clinical presentation and extent of venous thrombosis predict likelihood and type of recurrence? A patient-level meta-analysis. J Thromb Haemost. 2010; 8(II): 2436-2442, doi: 10.1111/j.1538-7836.2010.04022.x, indexed in Pubmed: 20723032.

36. Tomkowski WZ, Davidson BL, Wisniewska J, et al. Accuracy of compression ultrasound in screening for deep venous thrombosis in acutely ill medical patients. Thromb Haemost. 2007; 97(2): 191-194, indexed in Pubmed: 17264946.

37. Stein PD, Goodman LR, Hull RD, et al. Diagnosis and management of isolated subsegmental pulmonary embolism: review and assessment of the options. Clin Appl Thromb Hemost. 2012; I8(I): 20-26, doi: 10.1177//0760296/1422363, indexed in Pubmed: 21949040.

38. Wojtukiewicz MZ, Sierko E, Tomkowski W, et al. Wytyczne dotyczące profilaktyki I leczenia żylnej choroby zakrzepowo-zatorowej u chorych na nowotwory poddanych leczeniu zachowawczemu. Onkologia w Praktyce Klinicznej. 2016; 12: 67-91. 
39. Bochenek T, Nizankowski R. The treatment of venous thromboembolism with low-molecular-weight heparins. A meta-analysis. Thromb Haemost. 2012; 107(4): 699-716, doi: 10.1160/THII08-0565, indexed in Pubmed: 22318218.

40. Palareti G, Legnani C, Lee A, et al. A comparison of the safety and efficacy of oral anticoagulation for the treatment of venous thromboembolic disease in patients with or without malignancy. Thromb Haemost. 2000; 84(5): 805-810, indexed in Pubmed: 11127860.

4I. van Es N, Coppens M, Schulman S, et al. Direct oral anticoagulants compared with vitamin $\mathrm{K}$ antagonists for acute venous thromboembolism: evidence from phase 3 trials. Blood. 2014; 124(I2): 1968-1975, doi: 10.1182/blood-20|4-04-57|232, indexed in Pubmed: 24963045.

42. Lee AYY, Kamphuisen PW, Meyer G, et al. CATCH Investigators. Tinzaparin vs Warfarin for Treatment of Acute Venous Thromboembolism in Patients With Active Cancer: A Randomized Clinical Trial. JAMA. 2015; 314(7): 677-686, doi: 10.100I/ jama.2015.9243, indexed in Pubmed: 26284719.

43. Akl EA, Labedi N, Barba M, et al. Anticoagulation for the long-term treatment of venous thromboembolism in patients with cancer. Cochrane Database Syst Rev. 20I I(6): CD006650, doi: 10.1002/14651858.CD006650.pub3, indexed in Pubmed: 21678361.

44. Francis CW, Kessler CM, Goldhaber SZ, et al. Treatment of venous thromboembolism in cancer patients with dalteparin for up to 12 months: the DALTECAN Study. J Thromb Haemost. 2015; 13(6): 1028-1035, doi: 10.1111/jth.12923, indexed in Pubmed: 2582794I.

45. Prandoni P. Below-Knee Elastic Compression Stockings To Prevent the Post-Thrombotic Syndrome. Annals of Internal Medicine. 2004; I4I(4): 249, doi: 10.7326/0003-48|9-|4I-4200408170-00004.

46. Kahn SR, Comerota AJ, Cushman M, et al. American Heart Association Council on Peripheral Vascular Disease, Council on Clinical Cardiology, and Council on Cardiovascular and Stroke Nursing. The postthrombotic syndrome: evidence-based prevention, diagnosis, and treatment strategies: a scientific statement from the American Heart Association. Circulation. 2014; 130(18): 1636-1661, doi: 10.1161/CIR.00000000000000I30, indexed in Pubmed: 25246013.

47. Kahn SR, Shapiro S, Wells PS, et al. SOX trial investigators. Compression stockings to prevent post-thrombotic syndrome: a randomised placebo-controlled trial. Lancet. 2014; 383(9920): 880-888, doi: $10.1016 / 50140-6736(13) 61902-9$, indexed in Pubmed: 24315521.

48. Kahn SR, Shapiro S, Ducruet T, et al. Graduated compression stockings to treat acute leg pain associated with proximal DVT. A randomised controlled trial. Thromb Haemost. 2014; II2(6): I |37-I |4I, doi: 10.1160/THI4-05-0430, indexed in Pubmed: $\underline{25183442}$.

49. Kuo WT. Endovascular therapy for acute pulmonary embolism. J Vasc Interv Radiol. 2012; 23(2): 167-79.e4; quiz 179, doi: 10.1016/j.jvir.2011.10.012, indexed in Pubmed: 22192633.

50. Liang NL, Avgerinos ED, Marone LK, et al. Catheter-directed interventions for acute pulmonary embolism. J Vasc Surg. 2015; 6I(2): 559-565, doi: 10.1016/i.jvs.2014.10.036, indexed in Pubmed: 25524824.

5I. Jaff MR, McMurtry MS, Archer SL, et al. American Heart Association Council on Cardiopulmonary, Critical Care, Perioperative and Resuscitation, American Heart Association Council on Peripheral Vascular Disease, American Heart Association Council on Arteriosclerosis, Thrombosis and Vascular Biology. Management of massive and submassive pulmonary embolism, iliofemoral deep vein thrombosis, and chronic thromboembolic pulmonary hypertension: a scientific statement from the American Heart Association. Circulation. 20I I; 123(16): 1788-1830, doi: 10.1|6|/CIR.0b0|3e3|82|49|4f, indexed in Pubmed: 21422387.

52. Kucher N, Boekstegers P, Müller OJ, et al. Randomized, controlled trial of ultrasound-assisted catheter-directed thrombolysis for acute intermediate-risk pulmonary embolism. Circulation. 2014; 129(4): 479-486, doi: 10.116I/CIRCULATIONAHA. I 1 3.005544, indexed in Pubmed: 24226805.

53. Decousus $H$, Leizorovicz $A$, Parent $F$, et al. A clinical trial of vena caval filters in the prevention of pulmonary embolism in patients with proximal deep-vein thrombosis. Prévention du Risque d'Embolie Pulmonaire par Interruption Cave Study Group. N Engl J Med. 1998; 338(7): 409-4I5, doi: 10.1056/ NEJMI9980212338070I, indexed in Pubmed: 9459643.

54. Hajduk B, Tomkowski WZ, Malek G, et al. Vena cava filter occlusion and venous thromboembolism risk in persistently anticoagulated patients: a prospective, observational cohort study. Chest. 2010; 137(4): 877-882, doi: 10.1378/chest.09-1533, indexed in Pubmed: 19880907.

55. Stein PD, Matta F, Stein PD, et al. Vena cava filters in unstable elderly patients with acute pulmonary embolism. Am J Med. 2014; 127: 222-225, doi: 10.1016/j.amimed.2013.11.003, indexed in Pubmed: 24280176.

56. Stein PD, Matta F, Keyes DC, et al. Impact of vena cava filters on in-hospital case fatality rate from pulmonary embolism. Am J Med. 2012; 125(5): 478-484, doi: 10.1016/i.amjmed.2011.05.025, indexed in Pubmed: 22310013.

57. Muriel A, Jiménez D, Aujesky D, et al. RIETE Investigators. Survival effects of inferior vena cava filter in patients with acute symptomatic venous thromboembolism and a significant bleeding risk. J Am Coll Cardiol. 2014; 63(16): 1675-1683, doi: 10.1016/j.jacc.2014.01.058, indexed in Pubmed: 24576432.

58. Prasad V, Rho J, Cifu A. The inferior vena cava filter: how could a medical device be so well accepted without any evidence of efficacy? JAMA Intern Med. 2013; 173(7): 493-5; discussion 495, doi: 10.1001/jamainternmed.2013.2725, indexed in Pubmed: 23552611 .

59. Girard P, Meyer G, Parent F, et al. Medical literature, vena cava filters and evidence of efficacy. A descriptive review. Thromb Haemost. 20I4; III (4): 76I-769, doi: 10.1I60/THI3-07-060I, indexed in Pubmed: 24285013.

60. Mismetti P, Laporte S, Pellerin O, et al. PREPIC2 Study Group. Effect of a retrievable inferior vena cava filter plus anticoagulation vs anticoagulation alone on risk of recurrent pulmonary embolism: a randomized clinical trial. JAMA. 2015; 313(16): 1627-1635, doi: 10.1001/jama.2015.3780, indexed in Pubmed: 25919526.

61. Pollack CV, Reilly PA, Eikelboom J, et al. Idarucizumab for Dabigatran Reversal. N Engl J Med. 2015; 373(6): 5I I-520, doi: 10.1056/NEJMoal502000, indexed in Pubmed: 26095746.

62. Connolly SJ, Milling TJ, Eikelboom JW, et al. ANNEXA-4 Investigators. Andexanet Alfa for Acute Major Bleeding Associated with Factor Xa Inhibitors. N Engl J Med. . 2016; 375: | |3 |- | |4| .

63. Siegal DM, Curnutte JT, Connolly SJ, et al. Andexanet Alfa for the Reversal of Factor Xa Inhibitor Activity. N Engl J Med. 20I5; 
373(25): 24I3-2424, doi: 10.1056/NEJMoal510991, indexed in Pubmed: 26559317.

64. Tomkowski W, Chmielewski D, Gaciong Z, et al. Wytyczne postępowania w nagłych i planowych sytuacjach klinicznych, mogących zaistnieć u chorych leczonych doustnymi, bezpośrednimi inhibitorami aktywnego czynnika $X$ oraz aktywnego czynnika II. Acta Angiologica. 2012; 18: 40-49.

65. Kahn SR, Comerota AJ, Cushman M, et al. American Heart Association Council on Peripheral Vascular Disease, Council on Clinical Cardiology, and Council on Cardiovascular and Stroke Nursing. The postthrombotic syndrome: evidence-based prevention, diagnosis, and treatment strategies: a scientific statement from the American Heart Association. Circulation. 2014; 130(I8): 1636-1661, doi: 10.1161/CIR.0000000000000|30, indexed in Pubmed: 25246013.

66. O'Donnell TF, Passman MA, Marston WA, et al. Society for Vascular Surgery, American Venous Forum. Management of venous leg ulcers: clinical practice guidelines of the Society for Vascular Surgery ${ }^{\circledR}$ and the American Venous Forum. J Vasc Surg. 2014; 60(2 Suppl): 3S-59S, doi: 10.1016/j.jvs.2014.04.049, indexed in Pubmed: 24974070.

67. Ten Cate-Hoek AJ, Prins MH, Wittens CHA, et al. Postintervention duration of anticoagulation in venous surgery. Phlebology. 2013; 28 Suppl I: 105-III, doi: 10.1177/02683555134764I5, indexed in Pubmed: 23482544.

68. Weitz JI, Lensing AWA, Prins MH, et al. EINSTEIN CHOICE Investigators. Rivaroxaban or Aspirin for Extended Treatment of Venous Thromboembolism. N Engl J Med. 2017; 376(13): |21 I-1222, doi: 10.1056/NEJMoa 17005 I8, indexed in Pubmed: 28316279 .

69. Urbanek T, Krasiński Z, Kostrubiec M, et al. Wytyczne profilaktyki przeciwzakrzepowej u chorych onkologicznych, ze szczególnym uwzględnieniem pacjentów leczonych operacyjnie. Acta Angiologica. 2016; 22: 103-136.

\section{Appendix}

The Wells score for the assessment of the clinical probability of deep vein thrombosis

\begin{tabular}{|l|c|}
\hline Active malignancy (treated or diagnosed within the previous six months) & Score \\
\hline Paralysis, paresis, or recent plaster immobilization of a lower extremity & I \\
\hline Recently bedridden for more than three days or major surgery within four weeks & I \\
\hline Localized tenderness along the distribution of the deep venous system & I \\
\hline Entire leg swollen & I \\
\hline $\begin{array}{l}\text { Calf swelling by more than 3 cm when compared to the asymptomatic leg (measured I0 cm below } \\
\text { tibial tuberosity) }\end{array}$ & I \\
\hline Pitting edema (greater in the symptomatic leg) & I \\
\hline Collateral superficial veins (nonvaricose) & -2 \\
\hline Alternative diagnosis as likely or more likely than that of deep venous thrombosis & \\
\hline Interpretation & Overall score \\
\hline Clinical probability & $\leq 0$ \\
\hline Low & I-2 \\
\hline Moderate & $\geq 3$ \\
\hline High & \\
\hline
\end{tabular}

alf symptoms are present in both legs, assess the limb with more severe symptoms 
The Wells score for the assessment of the clinical probability of pulmonary embolism

\begin{tabular}{|c|c|c|}
\hline Variable & $\begin{array}{l}\text { Original version } \\
\text { (score) }\end{array}$ & $\begin{array}{l}\text { Simplified version } \\
\text { (score) }\end{array}$ \\
\hline \multicolumn{3}{|l|}{ Predisposing factors } \\
\hline Previous deep vein thrombosis (DVT) or pulmonary embolism (PE) & 1.5 & $\mathrm{I}$ \\
\hline Surgery or immobilization or in the previous four weeks & 1.5 & 1 \\
\hline Active malignancy & 1 & 1 \\
\hline Symptoms: hemoptysis & $\mathrm{I}$ & 1 \\
\hline \multicolumn{3}{|l|}{ Signs } \\
\hline Heart rate $\geq 100 \mathrm{bpm}$ & 1.5 & 1 \\
\hline Clinical symptoms and signs of DVT & 3 & 1 \\
\hline Clinical evaluation: other diagnosis less likely than PE & 3 & 1 \\
\hline \multicolumn{3}{|l|}{ Interpretation } \\
\hline \multicolumn{3}{|l|}{ Clinical probability (3 levels, original version) - overall score } \\
\hline Low $0-1$ & Moderate $2-6$ & High $\geq 7$ \\
\hline \multicolumn{3}{|l|}{ Clinical probability (2 levels, original version) - overall score } \\
\hline PE unlikely $0-4$ & \multicolumn{2}{|c|}{ PE likely $>4$} \\
\hline \multicolumn{3}{|l|}{ Clinical probability (2 levels, simplified version) - overall score } \\
\hline PE unlikely $0-1$ & \multicolumn{2}{|c|}{ PE likely $\geq 2$} \\
\hline
\end{tabular}

Evaluation of the clinical probability of pulmonary embolism using the revised Geneva score

\begin{tabular}{|c|c|c|}
\hline Variable & $\begin{array}{l}\text { Original version } \\
\text { (score) }\end{array}$ & $\begin{array}{l}\text { Simplified version } \\
\text { (score) }\end{array}$ \\
\hline \multicolumn{3}{|l|}{ Predisposing factors } \\
\hline Age $>65$ years & $\mathrm{I}$ & 1 \\
\hline Previous deep vein thrombosis (DVT) or pulmonary embolism (PE) & 3 & $\mathrm{I}$ \\
\hline Surgery or fracture within one month & 2 & $\mathrm{I}$ \\
\hline Active malignancy & 2 & $\mathrm{I}$ \\
\hline \multicolumn{3}{|l|}{ Symptoms } \\
\hline Unilateral leg pain & 3 & $\mathrm{I}$ \\
\hline Hemoptysis & 2 & $\mathrm{I}$ \\
\hline \multicolumn{3}{|l|}{ Signs } \\
\hline \multirow{2}{*}{ Heart rate } & $75-94 \mathrm{bpm}-3$ & $\mathrm{I}$ \\
\hline & $\geq 95 \mathrm{bpm}-5$ & 2 \\
\hline Pain on deep palpation of a lower limb and unilateral edema & 4 & 1 \\
\hline \multicolumn{3}{|l|}{ Interpretation } \\
\hline \multicolumn{3}{|l|}{ Clinical probability (3 levels, original version) - overall score } \\
\hline Low $0-3$ & Moderate 4-10 & High $\geq \mathrm{II}$ \\
\hline \multicolumn{3}{|l|}{ Clinical probability (3 levels, simplified version) - overall score } \\
\hline Low $0-1$ & Moderate 2-4 & High $\geq 5$ \\
\hline \multicolumn{3}{|l|}{ Clinical probability (2 levels, original version) - overall score } \\
\hline PE unlikely $0-5$ & & PE likely $\geq 6$ \\
\hline \multicolumn{3}{|l|}{ Clinical probability (2 levels, simplified version) - overall score } \\
\hline PE unlikely $0-2$ & & PE likely $\geq 3$ \\
\hline
\end{tabular}


Evaluation of prognosis in pulmonary embolism

\begin{tabular}{|c|c|c|}
\hline Prognostic factor & PESI (score) & sPESI (score) \\
\hline Age & Age in years & I (if $>80$ years) \\
\hline Male gender & 10 & - \\
\hline Malignancy & 30 & $\mathrm{I}$ \\
\hline Chronic heart failure & 10 & \multirow{2}{*}{ I } \\
\hline Chronic pulmonary disease & 10 & \\
\hline Pulse rate $\geq 1 \mathrm{I} 0 \mathrm{bpm}$ & 20 & $\mathrm{I}$ \\
\hline Systolic blood pressure $<100 \mathrm{~mm} \mathrm{Hg}$ & 30 & $\mathrm{I}$ \\
\hline Respiratory rate $>30$ breaths per minute & 20 & - \\
\hline Temperature $<36^{\circ} \mathrm{C}$ & 20 & - \\
\hline Altered mental status & 60 & - \\
\hline Arterial oxygen hemoglobin saturation $<90 \%$ & 20 & $\mathrm{I}$ \\
\hline \multicolumn{3}{|l|}{ Interpretation of the PESI score ${ }^{a}$} \\
\hline Score & \multicolumn{2}{|c|}{ Risk } \\
\hline $\begin{array}{l}\text { Class I: } \leq 65 \text { points } \\
\text { Class II: } 66-85 \text { points } \\
\text { Class III: } 86-105 \text { points } \\
\text { Class IV: } 106-125 \text { points } \\
\text { Class V: }>125 \text { points }\end{array}$ & $\begin{array}{r}\text { Very } \\
\text { Low } \\
\text { Moder } \\
\text { High } \\
\text { Very h }\end{array}$ & $\begin{array}{l}\%) \\
6) \\
1 \%) \\
\%) \\
5 \%)\end{array}$ \\
\hline \multicolumn{3}{|l|}{ Interpretation of the sPESI score ${ }^{a}$} \\
\hline Score & \multicolumn{2}{|c|}{ Risk } \\
\hline $\begin{array}{l}0 \text { points } \\
\geq I \text { point }\end{array}$ & \multicolumn{2}{|c|}{$\begin{array}{c}\text { I.0\% (95\% Cl: } 0-2.1 \%) \\
10.9 \%(95 \% \text { Cl: } 8.5-13.2 \%)\end{array}$} \\
\hline
\end{tabular}

Based on the 2014 ESC guidelines

PESI, Pulmonary Embolism Severity Index; sPESI, simplified Pulmonary Embolism Severity Index; Cl, confidence interval

${ }^{a} 30$-day mortality risk depending on the overall score.

The Padua prediction score for medical patients

\begin{tabular}{|l|r|}
\hline Active malignancy & 3 \\
\hline Previous venous thromboembolism & 3 \\
\hline Immobilization $\geq 3$ days & 3 \\
\hline Diagnosed hereditary or acquired thrombophilia & 3 \\
\hline Trauma or surgery $\leq$ I month) & 2 \\
\hline Age $\geq 70$ years & $\mathrm{I}$ \\
\hline Heart or respiratory failure & $\mathrm{I}$ \\
\hline Acute myocardial infarction or ischemic stroke & $\mathrm{I}$ \\
\hline Acute infection or rheumatological disorder & $\mathrm{I}$ \\
\hline Obesity (body mass index $\left.\geq 30 \mathrm{~kg} / \mathrm{m}^{2}\right)$ & $\mathrm{I}$ \\
\hline Hormonal therapy & $\mathrm{I}$ \\
\hline
\end{tabular}

Interpretation: score $\geq 4$ - high risk 